\title{
Liquid Hydrocarbons Production by the Steam Gasification of Used Tires: Energy Characteristics and Environmental Sustainability
}

\section{Kirill B Larionov}

Tomsk Polytechnic University: Nacional'nyj issledovatel'skij Tomskij politehniceskij universitet Konstantin Vitalyevich Slyusarskiy ( $\nabla$ slyuskonst@gmail.com )

National research Tomsk polytechnic univercity https://orcid.org/0000-0002-9732-9093

\section{Maria V Kirgina}

Tomsk Polytechnic University: Nacional'nyj issledovatel'skij Tomskij politehniceskij universitet

\section{Dmitriy V Gvozdyakov}

Tomsk Polytechnic University: Nacional'nyj issledovatel'skij Tomskij politehniceskij universitet llya A Bogdanov

Tomsk Polytechnic University: Nacional'nyj issledovatel'skij Tomskij politehniceskij universitet

\section{Andrey V Zenkov}

Tomsk Polytechnic University: Nacional'nyj issledovatel'skij Tomskij politehniceskij universitet

\section{Stanislav A Yankovsky}

Tomsk Polytechnic University: Nacional'nyj issledovatel'skij Tomskij politehniceskij universitet

\section{Vladimir E Gubin}

Tomsk Polytechnic University: Nacional'nyj issledovatel'skij Tomskij politehniceskij universitet

\section{Research Article}

Keywords: steam gasification, automobile tires, liquid hydrocarbons, technical characteristics, ignition, combustion

Posted Date: May 6th, 2021

DOl: https://doi.org/10.21203/rs.3.rs-337514/v1

License: (c) (i) This work is licensed under a Creative Commons Attribution 4.0 International License. Read Full License 
Liquid hydrocarbons production by the steam gasification of used tires: energy characteristics and environmental sustainability

Larionov K.B. ${ }^{1,2}$, Slysarsky K.V. ${ }^{1,2}$, Kirgina M.V. ${ }^{1}$, Gvozdyakov D.V. ${ }^{1}$, Bogdanov I.A. ${ }^{1}$, Zenkov A.V. ${ }^{1}$, Yankovsky S.A. ${ }^{1}$, Gubin V.E. ${ }^{1}$

${ }^{1}$ National Research Tomsk Polytechnic University, Tomsk, 634050, Russia

${ }^{2}$ National University of Science and Technology “MISIS”, Moscow, 119049, Russia

\section{*Corresponding author:}

Konstantin V. Slysarsky

Assistant professor

Energy Engineering School

National Research Tomsk Polytechnic University

Lenina avenue, 30, 634050, Tomsk, Russia

Tel: +7-3822-701-777 (1697)

slyuskonst@gmail.com

\section{Abstract}

The technical characteristics of liquid hydrocarbons obtained by steam gasification of the recycled automobile tires were studied as well as the features of their combustion process. Steam gasification of grinded tires was carried out in a tubular reactor using superheated steam with $500{ }^{\circ} \mathrm{C}$ temperature and $5 \mathrm{~kg} / \mathrm{h}$ mass flow rate. The obtained characteristics were compared with a traditional liquid fuel oil. The technical characteristics were determined via the standard analytical methods. An ignition and a combustion of liquid hydrocarbon samples were carried out in the combustion chamber at different temperatures of heating medium $\mathrm{T}_{\mathrm{g}}=450-700{ }^{\circ} \mathrm{C}$. Gas-phase combustion products were analyzed using a flow-through gas analyzer. It was found that liquid hydrocarbons were characterized by a low pour point $\left(-43^{\circ} \mathrm{C}-(-52){ }^{\circ} \mathrm{C}\right)$ and comparable to 
calorific value of traditional fuel oil $(40.56-43.3 \mathrm{MJ} / \mathrm{kg})$. In addition, the studied samples of liquid hydrocarbons were characterized by a lower ignition delay time (by $56 \%$, on average) and flame burning time (by $30 \%$, on average). Combustion process of the studied samples (including traditional fuel oil) was accompanied by the formation of micro-explosions.

Keywords: steam gasification, automobile tires, liquid hydrocarbons, technical characteristics, ignition, combustion

\section{Declarations}

Funding: This work was supported by Ministry of Science and Higher Education of Russian Federation (projects № FSWW-2020-0022 and № 075-00268-20-02 (ID: 07180-2020-0040)).

Conflicts of interest/Competing interests: The authors declare that they have no known conflict or competing financial interests or personal relationships that could have appeared to influence the work reported in this paper.

Availability of data and material: Data available within the article or its supplementary materials

Authors' contributions: Not applicable

\section{Graphical abstract}

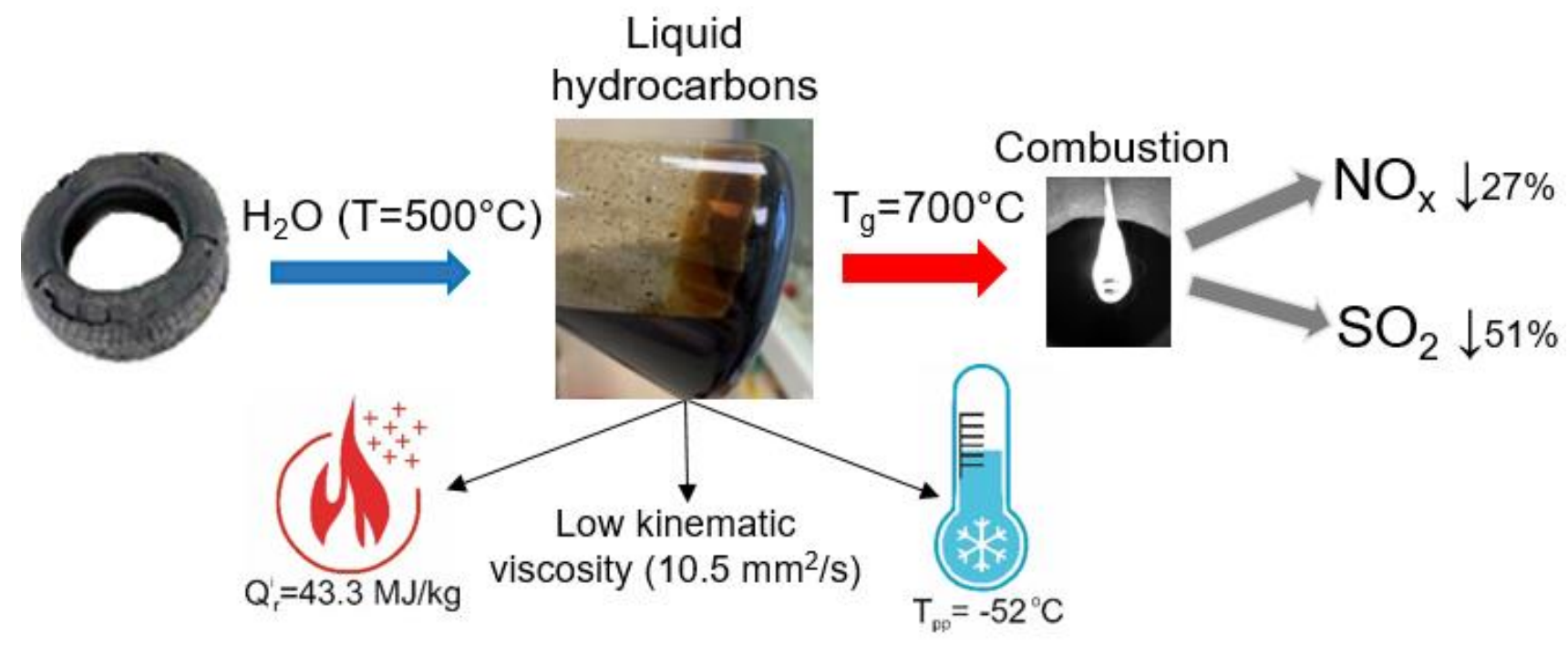




\section{Statement of novelty}

For the first time, complex experimental study have been carried out to determine the ignition and combustion characteristics of liquid hydrocarbons obtained by steam gasification of worn-out tires

\section{Introduction}

The annual production of cars worldwide for the past 10 years has been increased by $28 \%$ [1]. This leads to an inevitable increase in the number of used tires, which is a serious environmental problem due to the existing technological difficulties of their recycling and processing due to the composition heterogeneity and complex structure [2]. Thus, the disposal of used automobile tires in 2015 had reached almost 1 billion units [3]. At the same time, underground disposal of rubber waste is prohibited in many countries, due to regulation by the requirements for the management of industrial waste (Directive No. 1999/31/EC), as it can be a source of uncontrolled toxic fires and pollution.

One of the most promising ways to recycle automobile tires is the steam gasification technology [4-7]. Its advantages are explosion safety, neutralization of environmentally hazardous compounds in the vapor-gas mixture, higher the energy value of gas-phase products, activation of the carbon particles pore structure and the possibility of the smooth regulation of raw materials thermal conversion. The main products of gasification are liquid hydrocarbons, semi-coke, combustible gas and metal scrap. The semi-coke obtained is an analog of carbon black and can be returned to the technological cycle of rubber products manufacturing [8]. Another product (liquid hydrocarbons) consist of aromatic and aliphatic compounds [9-10]. They are of interest for the chemical and oil refining industries, as well as energy sector [11-13]. At the same time, the energy potential (having calorific value varied in range $40-44 \mathrm{MJ} / \mathrm{kg}$ [14] of this product is comparable to traditional fuel oil [15], which is used at power facilities, ships, railway transport, diesel engines [16] etc. The main advantage of liquid hydrocarbons obtained from rubber waste is a low pour 
point (up to $-87^{\circ} \mathrm{C}$ ) [17] and good rheological characteristics, low values of kinematic and dynamic viscosities [18], in particular, whose are of great importance to the operation of energy systems using such fuel at conditions of negative ambient temperatures (below $0{ }^{\circ} \mathrm{C}$ ) [19].

The paper [20] presents results of study on spraying and subsequent jet combustion of the obtained liquid hydrocarbons based on bio-oil. The authors determined that combustion of this fuel was characterized by formation of flame with characteristic combustion zones of volatile compounds (near the outlet of the nozzle) and char (near the outer boundary of the flame). Studies of jet fire process have a high practical value because they are close to the real conditions of operation of fuel-burning plants. However, it is not possible to ensure precise control of the combustion process parameters due to the large number of variables associated with the conditions and characteristics of fuel atomization as well as its mixing with the air. Study on the combustion of the single drop of liquid fuel allows exclusion of the large number of variables, which, in turn, allows to characterize the process in more detail [21].

The combustion of liquid hydrocarbon droplet obtained in the result of the pyrolysis of various carbon-containing raw materials is characterized by four successive stages: heating, evaporation of light compounds, thermal decomposition of heavier compounds and combustion of the coke residue formed [16, 20, 22-24]. In [16], the study on the fuel oil droplet combustion using high-speed video recording allowed to observe the formation of microbursts at the different stages of the process: from the beginning of moisture evaporation to the formation of coke residue. In particular, the authors found that with an increase in droplet size the time of their heating, ignition and subsequent combustion increases while the maximum temperature inside the droplet was almost constant and was varied in range $720-740{ }^{\circ} \mathrm{C}$. Similar effects were also observed in [21], where combustion of obtained by automobile tires pyrolysis oil droplets in free fall conditions in gaseous medium with different concentrations of oxygen (from 0 to 5 vol\%) was studied. The pyrolysis oil combustion process was accompanied by increase in the intensity of microbursts and subsequent formation of the small amount of soot (at maximal oxygen concentration). 
Seven stages of thermal transformation during bio-oil droplet combustion were identified into [25]. In particular, the stages of surface and bulk microbursts (stages 1 and 2, respectively), evaporation (stage 3), expansion in form of an additional microburst (stage 4) caused by the rapid increase in pressure inside the droplet [26], combustion (stage 5), smoldering (stage 6) and attenuation (stage 7) were identified. In [27-28], the appearance of microbursts during the combustion of liquid hydrocarbons is explained by the formation of a groups of small bubbles inside droplets. They open channels for the release of light volatile compounds during vaporization and initiate the microburst effect. Intensity of microbursts was increased with the temperature of the heating medium, which was also reported in some other articles [29-31].

Currently, the majority of the existing research in the field of liquid hydrocarbon droplets combustion is dedicated to bio-oils derived from lignocellulosic products. The pyrolysis oil obtained in the result of steam gasification of used tires have a high energetic potential, and can provide a partial replacement of traditional energy raw materials (fuel oil, in particular) within the program of waste rubber recycling, which will allow to reduce the expanses of households and businesses on energy resources.

This paper presents results of the experimental research on the combustion process of liquid hydrocarbons obtained via steam gasification of used automobile tires of summer type which were used for passenger cars.

\section{Material and methods}

\section{Initial samples of used automobile tires}

Four samples of used tires of passenger cars were used as initial material. In the current study, the summer type of tires was chosen due to their wide distribution worldwide and the possibility of all-season application (in countries with positive air temperatures throughout the year).

Tires were cut into chips via cutting tool with simultaneous removal of the metal cord. The size of the obtained chipped samples studied (width $\times$ height $\times$ length) was $7 \times 1 \times 7 \mathrm{~cm}$. The size 
variation was less than $1 \mathrm{~cm}$ for both sample width and length. Technical characteristics and elemental composition of the initial samples of used automobile tires are presented in table 1.

Table 1 Physical and chemical characteristics of samples of used automobile tires*

\begin{tabular}{|c|c|c|c|c|}
\hline \multirow{2}{*}{ Parameter } & \multicolumn{4}{|c|}{ Samples of used automobile tires } \\
\hline & \#1 & $\# 2$ & \#3 & \#4 \\
\hline Moisture content, wt $\%$ & 0.7 & 0.4 & 0.6 & 0.8 \\
\hline Ash content, wt $\%$ & 3.6 & 4.3 & 3.2 & 3.9 \\
\hline \multicolumn{5}{|c|}{ Elemental composition, wt $\%$} \\
\hline $\mathrm{C}$ & 84.5 & 84.2 & 85.4 & 81.9 \\
\hline $\mathrm{H}$ & 6.9 & 7.0 & 6.9 & 7.2 \\
\hline $\mathrm{N}$ & - & - & - & 1.7 \\
\hline$S$ & 1.7 & 1.7 & 1.6 & 1.3 \\
\hline $\mathrm{O}$ & 2.6 & 2.3 & 2.3 & 2.1 \\
\hline
\end{tabular}

* Moisture and ash content values were determined according to ISO 589:2008 and ISO 1171-97, respectively. Elemental composition of the samples was obtained using Flash $2000 \mathrm{CHNS}$ elemental analyzer (Thermo Fisher Scientific, USA).

Table 1 illustrates that samples of used automobile tires had similar technical characteristics and elemental composition, which were probably related to the technological features of the rubber manufacturing.

\section{Experimental installation of steam gasification}

The schematic diagram of experimental setup for steam gasification of used automobile tires is presented in Figure 1. 


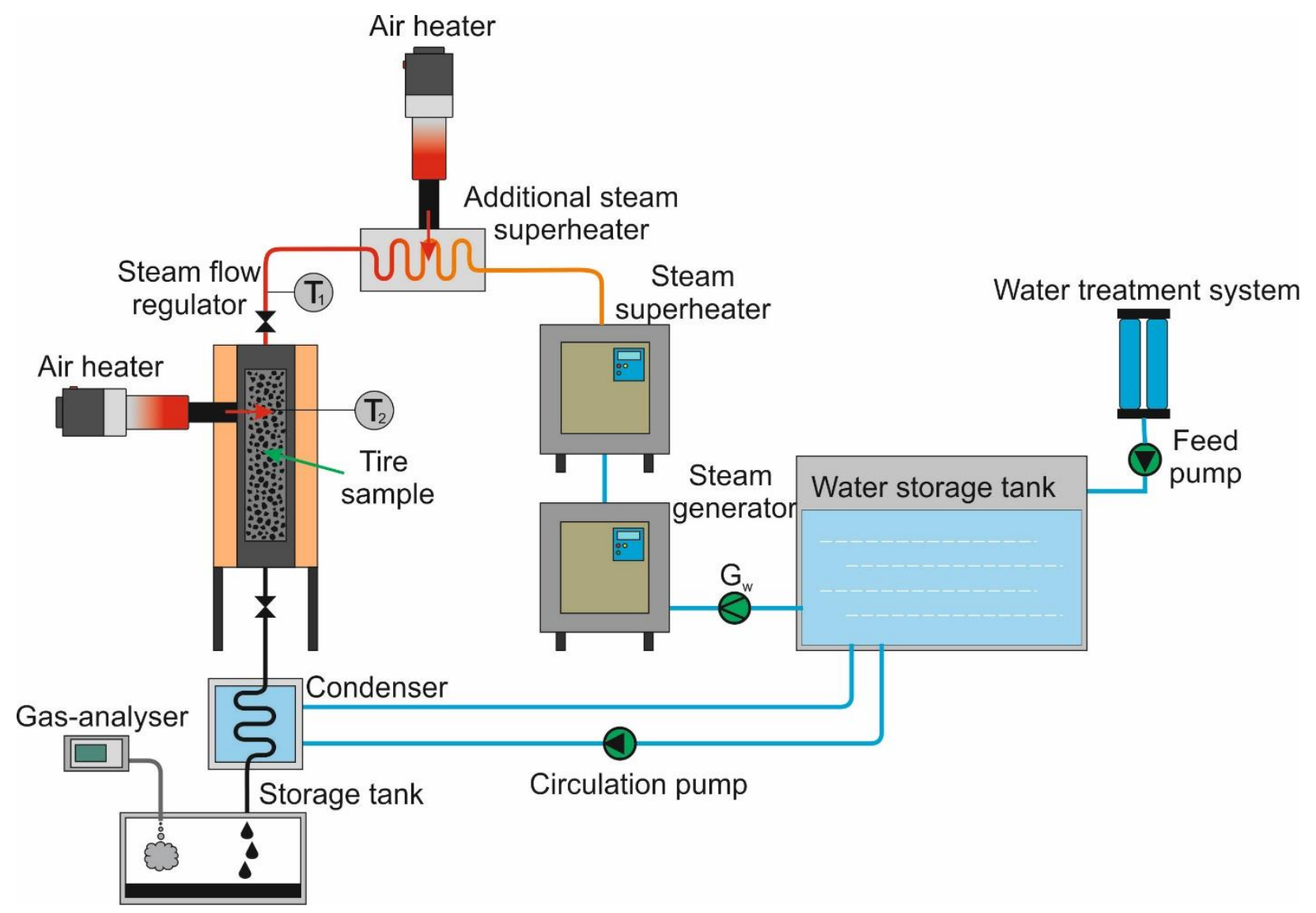

Fig.1 Schematic diagram of the experimental setup used for steam gasification of used automobile tires.

A $0.5 \mathrm{~kg}$ of used automobile tire sample was loaded into a tubular steam gasification reactor, in particular, in the container made of metal mesh tightly fixed into the inner volume of the reactor chamber. After that, the reactor was closed and tightly sealed. Then a regulating device was opened for constant steam flow through the chamber. The released during decomposition of the used automobile tires gases were removed together with steam and condensed in the tubular condenser. Obtained liquid products (mixture of water and liquid hydrocarbons) were drained into a storage tank. Saturated vapor was generated in a steam generator which was fed with chemically treated water from the water storage tank by pump. The steam flow rate was adjusted by a needle-type valve at the reactor inlet and regulated by a liquid flow meter installed before the steam generator. Then the heated to $120{ }^{\circ} \mathrm{C}$ steam consecutively passed through the first (electrical) and second (heated by hot air) stages of superheater, in which its temperature was increased to required value. Temperature control inside the reactor and intertubular gap (to maintain constant temperature by 
the air heater) was performed continuously using installed thermocouples $\left(\mathrm{T}_{1}\right.$ and $\left.\mathrm{T}_{2}\right)$ connected to a multi-channel thermocouple recorder.

Steam gasification of the studied samples of used automobile tires was carried out at $500{ }^{\circ} \mathrm{C}$ and $5 \mathrm{~kg} / \mathrm{h}$ flow rate for 1 hour. The sample weight was $0.5 \mathrm{~kg}$.

\section{Characterization of materials}

Before the analysis, the obtained condensed products of used automobile tires gasification were separated into liquid hydrocarbons and water using separating funnel. The liquid products later will be referred to as S1-S4 according to the designations of automobile tire samples used.

A sample of standard fuel oil was used to perform a comparative assessment of the obtained liquid hydrocarbon products. Such fuel oil is widely used in the energy complex [32-34]. This sample later will be referred to as S5.

Density of samples at $15^{\circ} \mathrm{C}$ as well as their kinematic and dynamic viscosities at $40{ }^{\circ} \mathrm{C}$ were determined via Stanbinger SVM3000 viscometer (Anton Paar, Austria), according to the ISO 12185:1996 "Crude Petroleum and Petroleum Products - Determination of Density - Oscillating U-tube Method" and ISO 3104:1994 "Petroleum Products. Transparent and Opaque Liquids. Determination of Kinematic Viscosity and Calculation of Dynamic Viscosity”, respectively.

The pour point $\left(\mathrm{T}_{\mathrm{pp}}\right)$ was determined via CRYO-T-05-01 liquid low-temperature thermostat (Termex, Russia), according to the method presented in ASTM D97-17b "Standard Test Method for Pour Point of Petroleum Products". The flash point $\left(\mathrm{T}_{\mathrm{fp}}\right)$ was determined in the open crucible using PE-TVO apparatus (Ekros, Russia), according to the method presented in ISO 2592:2000 "Determination of Flash and Fire Points - Cleveland Open Cup Method".

The ash content of the studied samples was determined via ISO 6245:2001 "Petroleum products - Determination of ash" method using a muffle furnace. At the beginning the samples were put into furnace which was heated to $300{ }^{\circ} \mathrm{C}$. Later this temperature was increased to $800{ }^{\circ} \mathrm{C}$ and the sample was kept in furnace until reaching constant mass. 
The calorific value of studied samples was determined using ABK-1 bomb calorimeter (Russian Energy Technologies, Russia). Elemental analysis was performed using Flash 2000 CHNS analyzer (Thermo Fisher Scientific, USA).

Thermal analysis of the liquid hydrocarbon samples was carried out using a differential thermal analyzer Netzsch STA 449 F3 Jupiter (Netzsch, Germany) in argon atmosphere (160 $\mathrm{ml} / \mathrm{min}$ ) at $10{ }^{\circ} \mathrm{C} / \mathrm{min}$ heating rate in the temperature range between 25 and $600{ }^{\circ} \mathrm{C}$. The sample weight was $\sim 20 \mathrm{mg}$.

\section{Droplet ignition and combustion of liquid hydrocarbon samples}

Study of ignition and subsequent combustion of single hydrocarbon droplets was carried out using experimental setup, schematic diagram of which is presented in Figure 2.

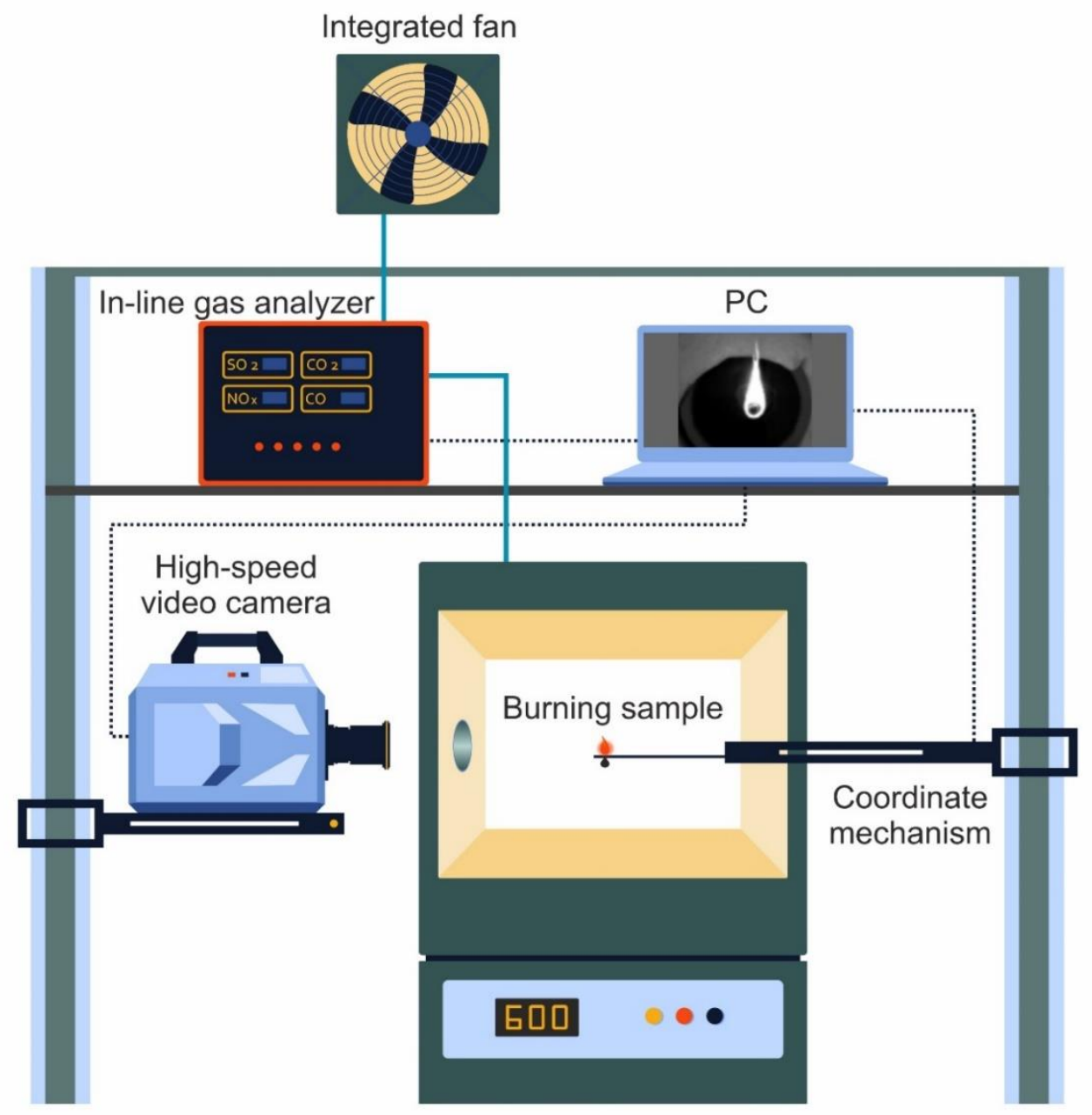

Fig. 2 Experimental setup for studying the combustion of liquid fuel droplets. 
The main elements of the setup were the combustion chamber in PM-1400 temperaturecontrolled furnace (Rusuniversal, Russia) with a digital temperature controller (accuracy of measurement $\pm 1-3{ }^{\circ} \mathrm{C}$ ) with $0,012 \mathrm{~m}^{3}$ volume; Fastcam SA4 5 high-frequency video camera (Photron, USA) with $1024 \times 1024$ pixels resolution (pixel size was $20 \mu \mathrm{m}$ ) with 12 bits color depth and $1000 \mathrm{fps}$ frequency of shooting; the platform of coordinate mechanism was used to supply the liquid hydrocarbon fuel droplets into the furnace with a less than $1 \mathrm{~mm}$ error of movement. The gas analysis was realized via Test 203 in-line gas analyzer (BONER, Russia).

The method of studying ignition and combustion of single droplet of liquid hydrocarbons samples included several steps. The required temperature was set (in the $450-700{ }^{\circ} \mathrm{C}$ range with $50{ }^{\circ} \mathrm{C}$ intermediate step) in a temperature-controlled furnace. Such temperatures were characteristic to the conditions of supplying sprayed liquid fuels to the furnace of modern boiler plants [35]. Then the droplet of liquid fuel was placed on the metal rod holder (made of steel wire) of the coordinate mechanism by mechanical dispenser, the stroke of which was calibrated at a coordinate of the center of the combustion chamber and driven by a PC. The average diameter of droplet was $1.5 \mathrm{~mm}( \pm 0.1 \mathrm{~mm})$. Video recording had been started simultaneously with the beginning of the rod movement into the combustion chamber. Composition of exhaust gases $(\mathrm{CO}$, $\mathrm{CO}_{2}, \mathrm{NO}_{\mathrm{x}}$ and $\mathrm{SO}_{2}$ ) was recorded using the in-line gas analyzer.

Comparative assessment of the characteristics of ignition and combustion at different temperatures of the heating medium was carried out by analyzing the times of ignition delay and flame burning, which were obtained using high-frequency video camera. Ignition delay time was considered to be the time interval between the moments of the holder entering the focus of the camera and the appearance of visible glow on the fuel surface. Burning time was considered from the moment of visible glow appearance to the sample burnout with the disappearance of visible flame. 
The fuel ignition process was considered to be stable if a well-visible flame was observed and the droplet was burned completely. At least 10 repetitive measurements were performed for each sample at each temperature of heating medium.

\section{Results and discussions}

\section{Characteristics of liquid hydrocarbons obtained by steam gasification of used} automobile tires

The amount of liquid hydrocarbons (expressed in percent of the initial mass of the automobile tire sample) obtained after steam gasification was following: S1 - 54.7; S2 - 57.1; $\mathrm{S} 3-53.9$ and $\mathrm{S} 4-57.4 \mathrm{wt} \%$.

The determined technical characteristics and elemental composition of studied liquid hydrocarbon samples are presented in Table 2 .

Table 2 Technical characteristics of the studied samples of liquid hydrocarbons

\begin{tabular}{|c|c|c|c|c|c|}
\hline \multirow{2}{*}{ Characteristic } & \multicolumn{5}{|c|}{ Fuel sample } \\
\hline & S1 & $\mathbf{S 2}$ & S3 & S4 & S5 \\
\hline Density at $15^{\circ} \mathrm{C}, \mathrm{kg} / \mathrm{m}^{3}$ & 932.1 & 928.9 & 945.0 & 938.0 & 950.6 \\
\hline Kinematic viscosity at $40^{\circ} \mathrm{C}, \mathrm{mm}^{2} / \mathrm{s}$ & 10.55 & 10.63 & 18.74 & 13.48 & 583.74 \\
\hline Dynamic viscosity at $40^{\circ} \mathrm{C}, \mathrm{mPa} \cdot \mathrm{s}$ & 9.66 & 9.69 & 17.47 & 12.43 & 545.69 \\
\hline $\mathrm{T}_{\mathrm{pp}},{ }^{\circ} \mathrm{C}$ & -51 & -52 & -49 & -43 & +10 \\
\hline $\mathrm{T}_{\mathrm{fp}},{ }^{\circ} \mathrm{C}$ & 85 & 82 & 73 & 83 & 175 \\
\hline Ash content, \% & \multicolumn{5}{|c|}{ traces } \\
\hline Calorific value, $\mathrm{MJ} / \mathrm{kg}$ & 42.36 & 43.30 & 41.76 & 40.56 & 43.89 \\
\hline \multicolumn{6}{|c|}{ Elemental composition, wt $\%$} \\
\hline $\mathrm{C}$ & 85.32 & 86.25 & 81.73 & 82.38 & 87.78 \\
\hline $\mathrm{H}$ & 10.72 & 10.98 & 10.61 & 10.33 & 9.88 \\
\hline
\end{tabular}




\begin{tabular}{|c|c|c|c|c|c|}
\hline $\mathrm{N}$ & 0.60 & 0.57 & 0.45 & - & 0.22 \\
\hline $\mathrm{S}$ & 0.79 & 0.76 & 0.77 & 0.64 & 1.81 \\
\hline $\mathrm{O}$ & 2.57 & 1.44 & 6.44 & 6.65 & 0.31 \\
\hline $\mathrm{H} / \mathrm{C}$ & 1.51 & 1.53 & 1.56 & 1.50 & 1.35 \\
\hline $\mathrm{O} / \mathrm{C}$ & 0.02 & 0.01 & 0.06 & 0.06 & - \\
\hline
\end{tabular}

Presented in Table 2 data indicate that kinematic and dynamic viscosities of samples S1-S4 at $40{ }^{\circ} \mathrm{C}$ which were by 40 times smaller compared to standard fuel oil sample S5. According to [13], the difference in the obtained viscosity values may be due to the presence of heavier compounds in the S5 sample, in contrast to the S1-S4 samples. Smaller viscosity of liquid hydrocarbons S1-S4 allows to simplify their transportation and spraying into energy equipment thus reducing energy spent on pretreatment of such fuel before application.

The S1-S4 samples were also characterized by lower pour point $\left(\mathrm{T}_{\mathrm{pp}}=-43-(-52){ }^{\circ} \mathrm{C}\right)$ compared to standard fuel oil $\left(\mathrm{T}_{\mathrm{pp}}=10^{\circ} \mathrm{C}\right)$. This could be relevant to energy enterprises operated into cold climate conditions. The significant difference in $\mathrm{T}_{\mathrm{pp}}$ value for $\mathrm{S} 1-\mathrm{S} 4$ samples could be connected to the significant content of light fractions, paraffin naphtene and aromatic hydrocarbons as well as to the low content of n-paraffin which freezes at positive temperatures [36]. Additionally, such samples had lower flash point temperature $\left(\mathrm{T}_{\mathrm{fp}}=73-85^{\circ} \mathrm{C}\right)$ compared to standard fuel oil $\left(\mathrm{T}_{\mathrm{fp}}=175{ }^{\circ} \mathrm{C}\right)$. This indicates more complex fractional composition of liquid hydrocarbons obtained via used automobile tires steam gasification compared to other fuel oil [37].

As it could be seen from the data presented in table 2, the sulfur content in S1-S4 samples is an average by 2 times lower compared to S5 fuel oil. This feature is undoubtedly important advantage of such fuel because during their combustion less sulfur oxide will be formed which, apart from anthropogenic effect, is causing intense corrosion of metal surfaces of tubes and other elements of boilers. 
The S5 sample was characterized by a higher carbon content (87.78 wt\%) and lower hydrogen and oxygen content (9.88 and $0.31 \mathrm{wt} \%$, respectively), which was also correlated with the data in [26]. This was likely due to the presence of a smaller amount of light hydrocarbons in the composition of this sample. It should also be noted that S1-S4 samples had higher values of $\mathrm{H} / \mathrm{C}$ and $\mathrm{O} / \mathrm{C}$ ratios (on average by $16 \%$ and $3 \%$, respectively) in contrast to S5.

Figure 3 shows the results of thermal decomposition of the studied samples of liquid hydrocarbons in an inert argon medium.

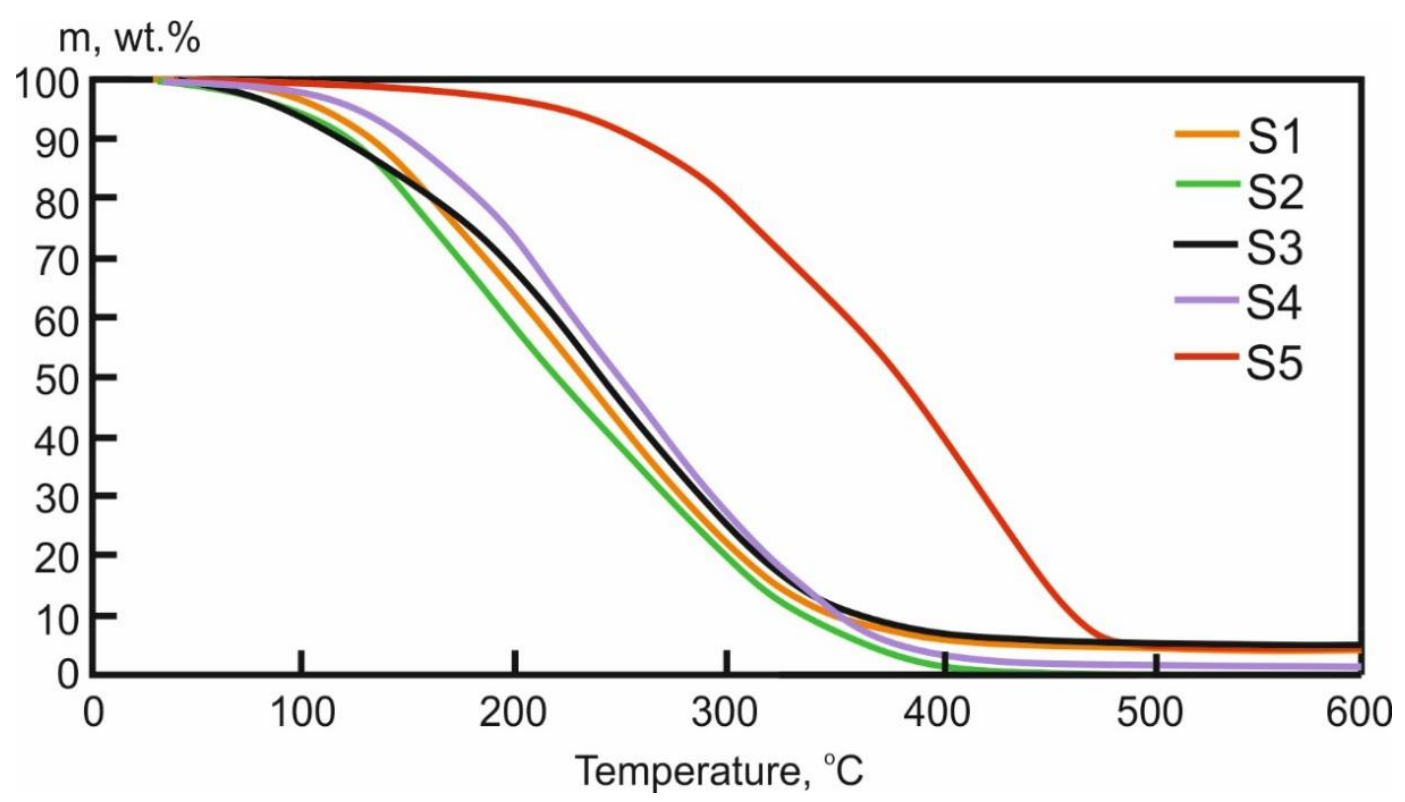

Fig. 3 TG curves for thermal decomposition of liquid hydrocarbon samples. Medium - argon $150 \mathrm{ml} / \mathrm{min}$, heating rate $-10{ }^{\circ} \mathrm{C} / \mathrm{min}$, sample weight $\approx 20 \mathrm{mg}$.

Comparison of obtained results (Figure 3a) revealed that TG curves characterizing the thermal decomposition of all studied samples (except S5 sample $\left(\mathrm{T}_{\mathrm{d}}=245^{\circ} \mathrm{C}\right)$ ) had similar nature and similar temperatures of the thermal decomposition beginning $\mathrm{T}_{\mathrm{d}}\left(105-123{ }^{\circ} \mathrm{C}\right)$. The difference in the determined values of the $\mathrm{T}_{\mathrm{d}}$ parameter was caused by the presence of highly reactive light hydrocarbons in the S1-S4 samples, which was also confirmed by the authors of other works $[16,25]$.

According to Figure 3a, the mass loss of S1-S4 samples in the temperature range of 25$100{ }^{\circ} \mathrm{C}$ was 2.0-5.1 wt $\%$; for S5 sample $-0.3 \mathrm{wt} \%$. Mass loss in this temperature range could be 
associated with the boiling of residual moisture and some petroleum fraction [38], for which characteristic temperature range of boiling was $40-100{ }^{\circ} \mathrm{C}$. For S1-S4 samples at $200{ }^{\circ} \mathrm{C}$ the mass loss was 24.8-36.8 wt\% which was associated with boiling and conversion of light gasoline fractions [39]. For S5 sample with presumably no light fraction it was $2.8 \mathrm{wt} \%$. The mass loss for the studied S1-S4 samples was 38.0-46.9 wt\% in the $200-300{ }^{\circ} \mathrm{C}$ temperature range corresponding to the boiling of the hydrocarbons fraction with intermediate molar mass (kerosene, in particular) [39]; for S5 sample - $16.4 \mathrm{wt} \%$. Finally, at a temperatures above $300{ }^{\circ} \mathrm{C}$, which referred to the boiling of heavy hydrocarbons [39], the mass loss of the studied S1-S4 samples was 18.1$25.6 \mathrm{wt} \%$, while for S5 sample it was $76.3 \mathrm{wt} \%$.

\section{Droplet ignition and combustion of liquid hydrocarbons}

Dependences of the ignition delay time of the studied hydrocarbon droplets on the heating medium temperature in range from 450 to $700{ }^{\circ} \mathrm{C}$ are presented in Figure 4.

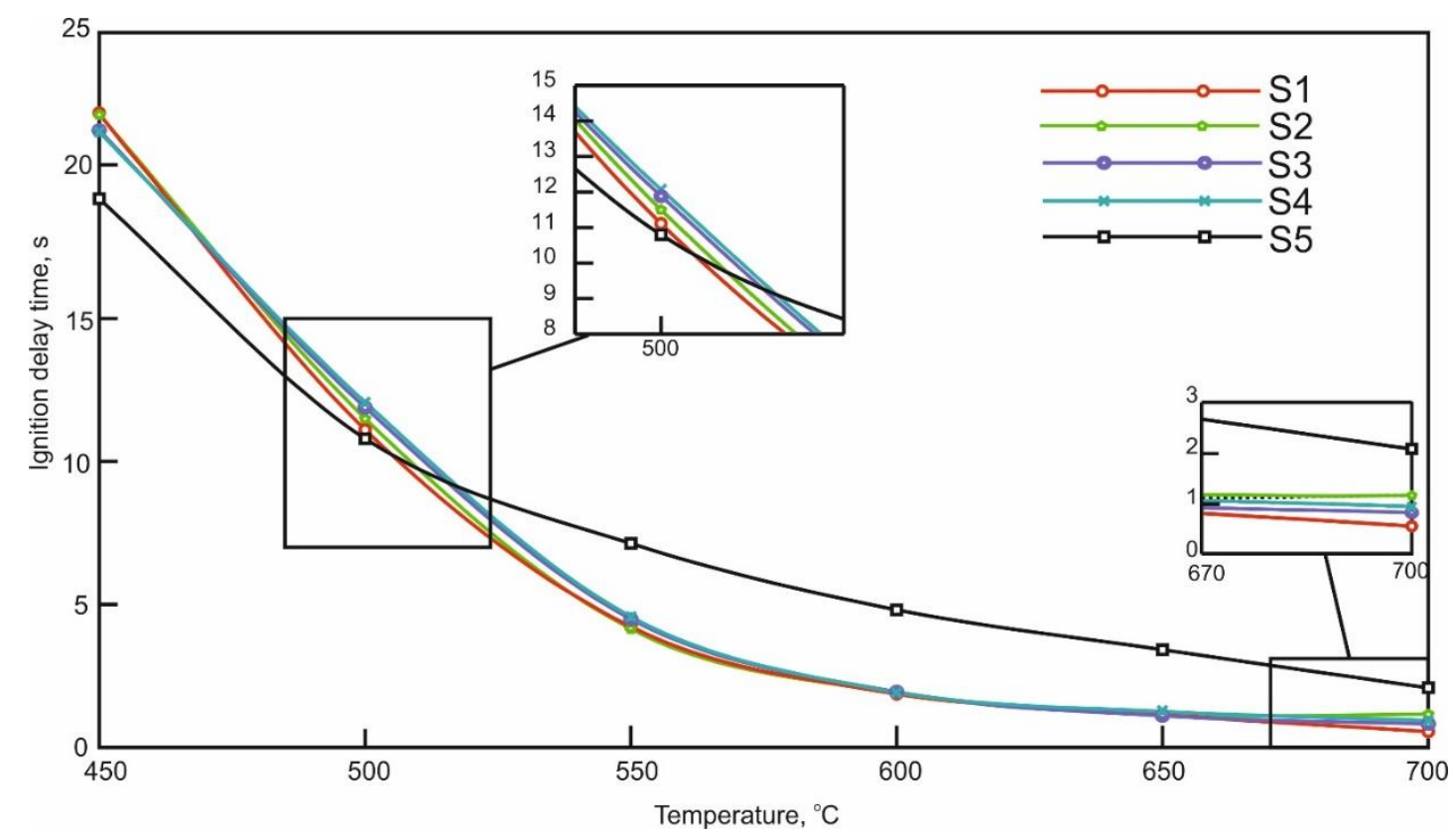

Fig. 4 Dependences of the ignition delay time of the studied hydrocarbon droplets on the heating medium temperature in range from 450 to $700{ }^{\circ} \mathrm{C}$.

For all samples the ignition delay time $\tau_{\mathrm{i}}$ was found to exponentially decrease with the increasing of heating medium temperature which was in good correspondence with earlier published articles [29-31]. The average ignition delay time of the studied samples was reduced by 
19.2 times with increase in the temperature from $450{ }^{\circ} \mathrm{C}$ to $700{ }^{\circ} \mathrm{C}$. Significant deviation in the character of ignition delay time $\tau_{\mathrm{i}}$ dependence on temperature (in comparison with samples S1-S4) was observed for standard fuel oil (sample S5) according to Figure 4. This difference could be explained by significantly different elemental composition (Table 2) as well as by the presence of light hydrocarbons in the composition of samples S1-S4.

Figure 5 shows the results (video frames) of experimental studies on ignition and combustion of single liquid hydrocarbon droplets at $700{ }^{\circ} \mathrm{C}$.
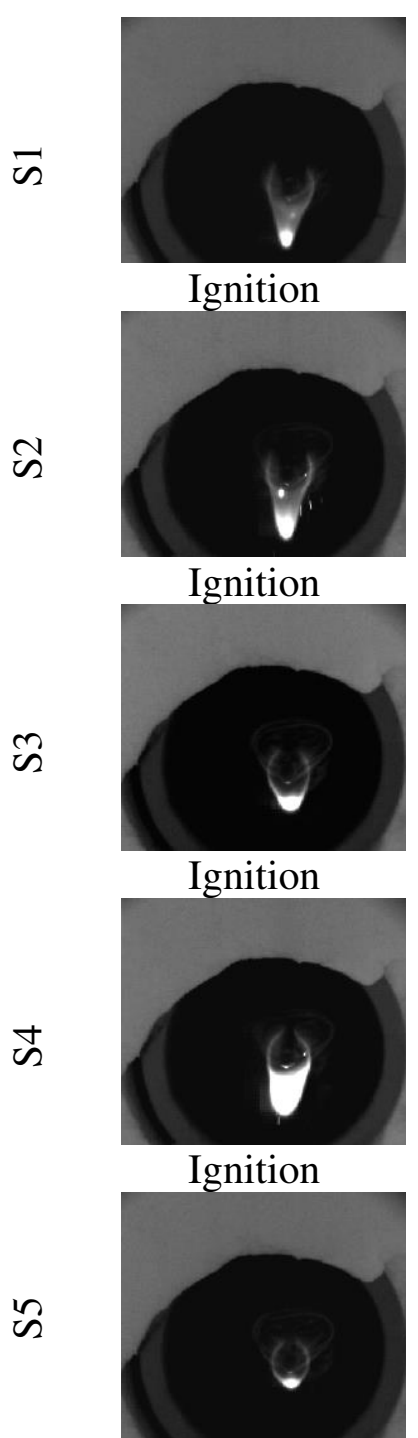

Ignition

a

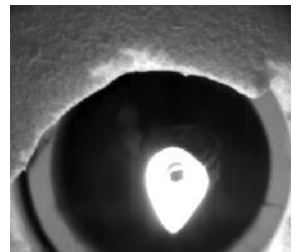

$\tau \approx 0.01 \mathrm{~s}$

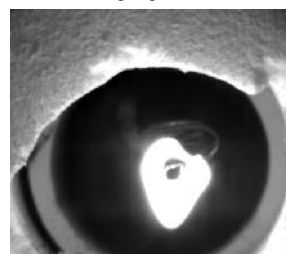

$\tau \approx 0.02 \mathrm{~s}$

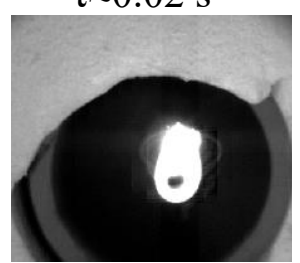

$\tau \approx 0.03 \mathrm{~s}$

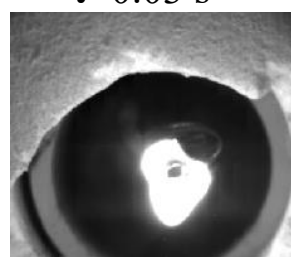

$\tau \approx 0.01 \mathrm{~s}$

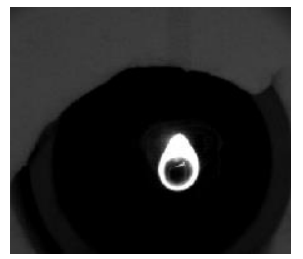

$\tau \approx 0.19 \mathrm{~s}$

b

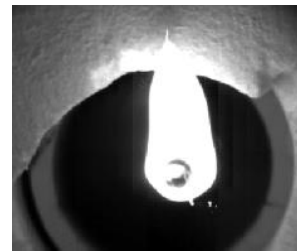

$\tau \approx 0.14 \mathrm{~s}$

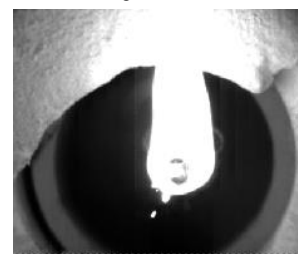

$\tau \approx 0.25 \mathrm{~s}$

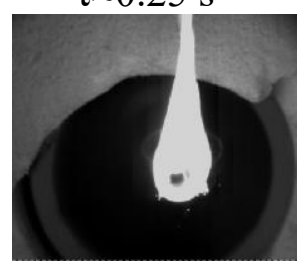

$\tau \approx 0.25 \mathrm{~s}$

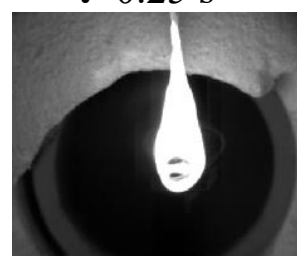

$\tau \approx 0.21 \mathrm{~s}$

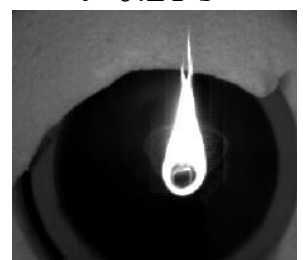

$\tau \approx 1.90 \mathrm{~s}$

c

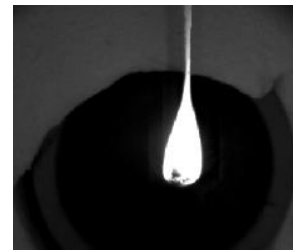

$\tau \approx 3.48 \mathrm{~s}$

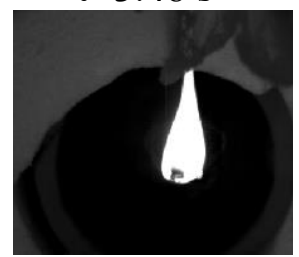

$\tau \approx 3.74 \mathrm{~s}$

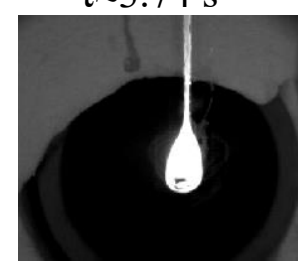

$\tau \approx 3.74 \mathrm{~s}$

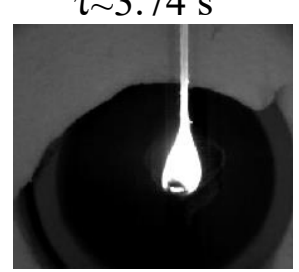

$\tau \approx 3.65 \mathrm{~s}$

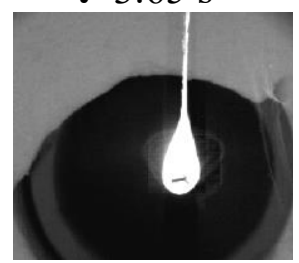

$\tau \approx 4.45 \mathrm{~s}$

d

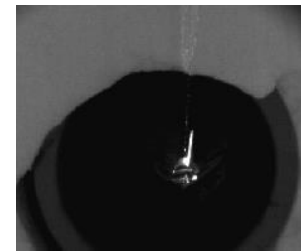

$\tau \approx 4.28 \mathrm{~s}$

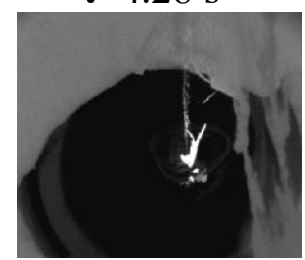

$\tau \approx 4.36 \mathrm{~s}$

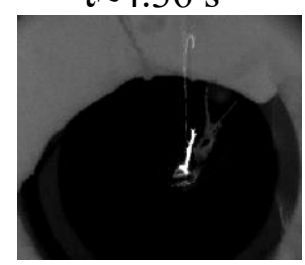

$\tau \approx 4.16 \mathrm{~s}$

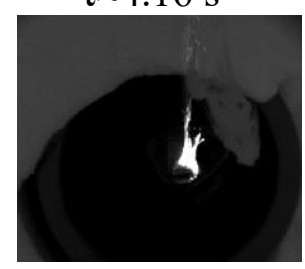

$\tau \approx 4.23 \mathrm{~s}$

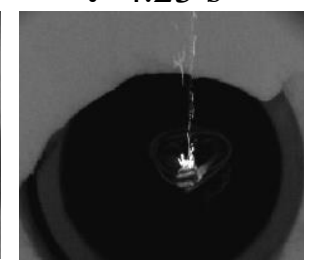

$\tau \approx 4.85 \mathrm{~s}$

$\mathrm{e}$

Fig. 5 Typical video frames of ignition and subsequent combustion of hydrocarbon droplets at $700{ }^{\circ} \mathrm{C}$ temperature of the heating medium ( $\mathrm{a}$ - ignition, $\mathrm{b}$ - flame formation, followed by expansion of the combustion front, $\mathrm{c}$ - increase in the intensity of flaming combustion, $\mathrm{d}-$ constriction of the combustion front, $\mathrm{e}$ - formation of the coke residue). 
The process of ignition and combustion of the studied hydrocarbons could be divided into several stages as it was done in [40]. The first stage was the inert heating of a single droplet. At the second stage, the processes of simultaneous intense evaporation, formation of volatile substances and a mixture of flammable gases were observed. The third stage was characterized by intense chemical interaction between fuel and oxidizer in a high-temperature gas environment. The fourth stage was connected to heterogeneous combustion of the coke residue.

Based on the obtained video frames, it is possible to formulate a physical model of the ignition and subsequent combustion of single droplets of hydrocarbons. Thus, the intense heating of sample with the characteristic initial size $(\mathrm{D}=1.5 \mathrm{~mm})$ begins after its introduction to the thermoregulated furnace. Then the components of hydrocarbons [40] start to evaporate from the near-surface layers of the droplet. The transformation of the droplet surface, change in its size along the longitudinal and transverse coordinates as well as change of its appearance (transition from "glossy" to "matte") identify this stage. These processes are more or less pronounced for the different samples of hydrocarbons, which are connected to the water content in their composition (Figure 3). As a result, a vapor cloud [16] with combustible gases [41] is formed near the surface of the droplet. The gas-phase ignition is realized when the minimal required concentrations and temperature of hydrocarbon-air mixture are reached (Figure 5a).

Formation of gradually developing flame around the droplet is observed after gas-phase ignition, without pronounced change in its surface. This may indicate that the primary evaporation of fuel's light hydrocarbons occurs at the surface of the droplet while the heavier components are subsequently concentrated in the char residue making the shell of the droplet more viscous [42].

Duration of microburst formation period depended significantly on the sample of liquid hydrocarbons studied. Thus, this effect had continuous character for S1-S4 samples and was observed throughout the combustion. It is also important to note that the intensity of microbursts, which manifested itself into the number of sparks formed, frequency of their occurrence and 
remoteness from the droplet surface was found to depend on the viscosity and composition of the studied fuels (Table 2). Thus, the stronger tendency to form microbursts could be referred to fuels with a high content of water and light hydrocarbons, as well as a lower viscosity (S1-S4 samples). The latter affected the tenacity of the surface film, through which the volumetric accumulations of formed flammable vapors were released. According to [43], the breaking point temperature of weak chemical bonds of heavy oil was close to $352{ }^{\circ} \mathrm{C}$ and the thermal cracking did not occur until the $427{ }^{\circ} \mathrm{C}$ temperature was reached. Thus, the formation of microbursts at the early stage of studied samples combustion (for S1-S4 samples this was more relevant) was associated with evaporation of light fuel components, and not with thermal decomposition of the fuel.

It is important to note that there was an intensive expansion of the combustion front at an early stage of flame burning stage for S1-S4 samples, the size of which exceeded the initial characteristic size of the droplet by several times (Figure 5b). Thus, the burnout of the combustible mixture of gases near the surface of the fuel droplet for these samples contributed to additional heating of the droplet itself. Later, the increase in the intensity of combustion with formation of a large flame (Figure 5c) with instable form occurred form (as a result of the formation of continuous microbursts). The surface of the droplet was drained with a noticeable narrowing of the combustion front after the burnout of light fuel components (Figure $5 \mathrm{~d}$ ) while the liquid components of the fuel were accumulated in the center of the droplet. The amount of energy released during gasphase combustion was enough to accelerate the evaporation of hydrocarbons from the liquid core thus accelerating the heterogeneous combustion front propagation from the droplet surface to its center until the burnout of hydrocarbons. In turn, for the S5 sample the formed flame was characterized by a smaller size and more stable shape.

The flame burning stage had been completed after the removal of volatile components and the resulting coke residue in the form of residual soot continued to burn (Figure 5 e) in a heterogeneous mode. This combustion stage was very short due to the high content of volatile 
components into the liquid hydrocarbon samples studied. Its duration was varied in range 0.1-0.6 s at the $700{ }^{\circ} \mathrm{C}$ depending on the composition of studied samples.

Dependences of the flame burning time of the liquid hydrocarbon droplets on the heating medium temperature (varied in range $500-700{ }^{\circ} \mathrm{C}$ ) are presented in Figure 6.

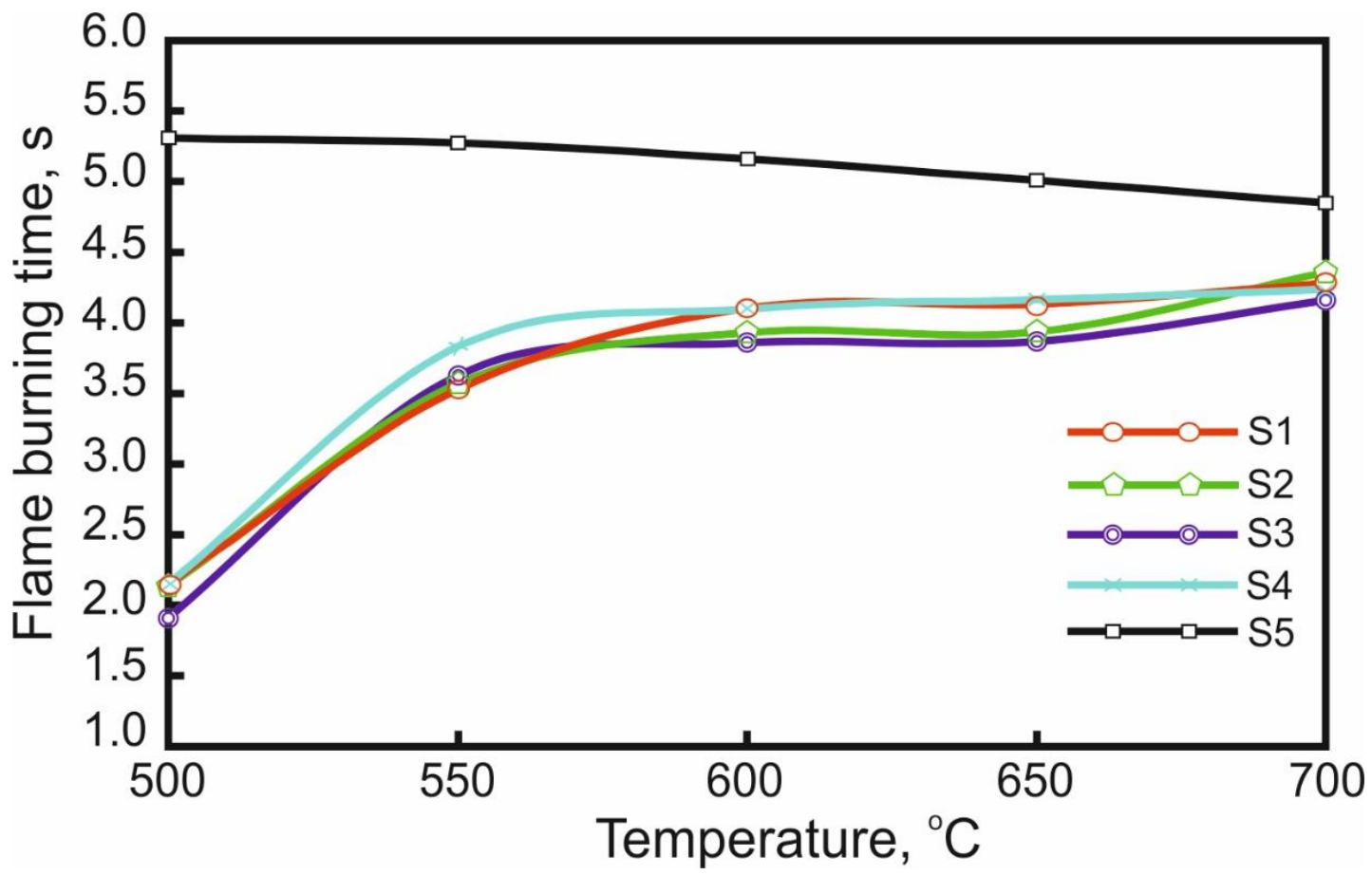

Fig. 6 Dependences of the flame burning time of the liquid hydrocarbon droplets on the heating medium temperature in range from 500 to $700{ }^{\circ} \mathrm{C}$.

The highest flame burning time in the entire temperature range studied $\left(500-700{ }^{\circ} \mathrm{C}\right)$ was observed for the standard fuel oil (S5 sample), characterized by a low content of light hydrocarbons (Figure 3, table 3) with high reactivity. As the temperature of the heating medium increased, a slight decrease in the flame burning time $\left(\Delta \tau_{\mathrm{f}}=0.46 \mathrm{~s}\right)$ was observed for this sample. At the same time, different relationship was observed for S1-S4 samples, manifested in an increase of $\tau_{\mathrm{f}}$ parameter from 2.1 to $4.3 \mathrm{~s}$ on average. This effect may be associated with surface coking of the droplet as a result of a sharp increase in the temperature of heating medium, which makes it difficult for the oxidizer to diffuse to the combustible liquid hydrocarbons. The obtained 
dependence of the flame burning time of the studied liquid hydrocarbons on the heating medium temperature was in good agreement with the results of other authors [44].

\section{Analysis of gas-phase combustion products}

Figure 7 shows the maximum concentration of various gas-phase compounds $\left(\mathrm{CO}, \mathrm{CO}_{2}\right.$, $\mathrm{SO}_{2}, \mathrm{NO}_{\mathrm{x}}$ ) in the combustion products of the studied samples of liquid hydrocarbons at different temperatures of the heating medium $\left(\mathrm{T}_{\mathrm{g}}=500-700{ }^{\circ} \mathrm{C}\right)$.
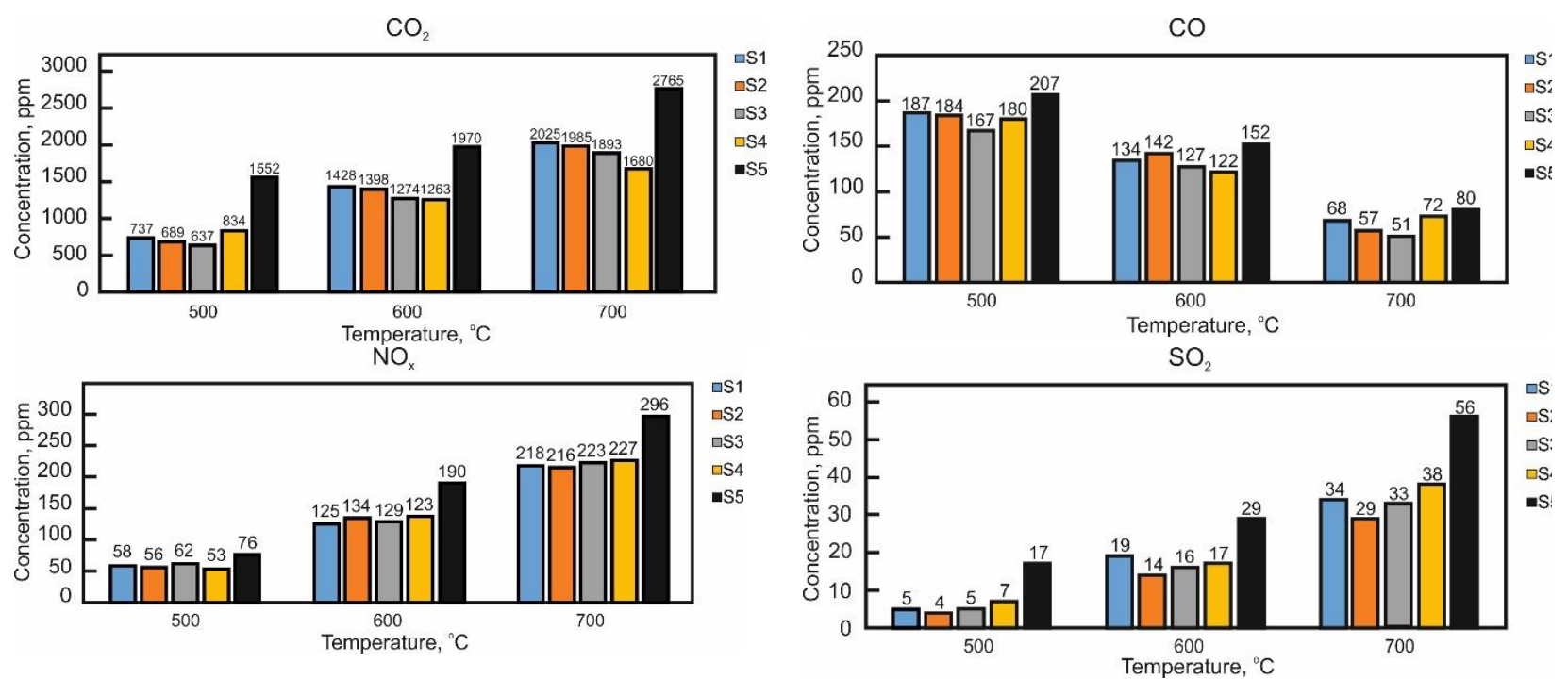

Fig. 7 Concentration maxima of gas-phase compounds $\left(\mathrm{CO}, \mathrm{CO}_{2}, \mathrm{SO}_{2}\right.$ and $\left.\mathrm{NO}_{\mathrm{x}}\right)$ in the released combustion products of liquid hydrocarbons at different temperatures of the heating medium.

It could be seen that there was a decrease in the concentration of $\mathrm{CO}$ in the composition of the gas-phase combustion products (on average by $64 \%$ ) with the increase in the heating medium temperature, due to intensification of the combustion process of liquid hydrocarbons at higher temperatures. In turn, there was an increase in the concentration of $\mathrm{CO}_{2}$ in gas-phase combustion products on average from 900 to $2070 \mathrm{ppm}$ with the growth of $\mathrm{T}_{\mathrm{g}}$ for all studied samples. In this case, the dependence of the maximum $\mathrm{CO}_{2}$ concentration on the heating medium temperature $\mathrm{T}_{\mathrm{g}}$ was linear. Increase in $\mathrm{CO}_{2}$ concentration was most likely caused by the more intensive oxidation of the formed $\mathrm{CO}$ at a relatively constant value of total combustion time of the liquid hydrocarbons (Figure 6) at high temperatures of the heating medium $\left(600-700{ }^{\circ} \mathrm{C}\right)$. 
Lower values of the concentration peaks of $\mathrm{CO}$ and $\mathrm{CO}_{2}$ (on average by $16 \%$ and $39 \%$, respectively) were observed for S1-S4 samples compared to the S5 sample, which correlated with their elemental composition (Table 2) and the intensity of microbursts observed at an early stage of combustion. These microbursts also contributed to a more intensive oxidation of the carbon monoxide formed due to the intensification of interactions between combustible fuel components and oxidizing environment. In particular, this was due to the fact that water in micro-droplets evaporates first during liquid fuel heating, since its boiling temperature is smaller compared to liquid hydrocarbons. This phenomena occurs at a heating medium temperature that is much higher than the boiling point of water. The dispersion of fuel droplets promotes for their mixing with air, which, in turn, boosts the air-fuel interactions. Thus, this results into increasing in the secondary atomization of the fuel during its combustion with formation of flammable gases such as $\mathrm{CO}$ and $\mathrm{H}_{2}$.

In contrast to the studied liquid hydrocarbons (S1-S4), large values of concentration maxima of $\mathrm{SO}_{2}$ and $\mathrm{NO}_{x}$ were observed for the $\mathrm{S} 5$ sample (on average by $51 \%$ and $27 \%$, respectively), which were caused by the higher content of sulfur and nitrogen in the composition of this sample itself (table 2). As the $\mathrm{T}_{\mathrm{g}}$ temperature increases, the concentration maxima of sulfur and nitrogen oxides release increase (on average by 5 and 4 times, respectively), which is also in good agreement with the results of other authors [45].

According to [45], formation of $\mathrm{NO}_{\mathrm{x}}$ in the result of the oxidation of fuel nitrogen is the predominant mechanism for the considered liquid hydrocarbons, since the formation of prompt and thermal $\mathrm{NO}_{\mathrm{x}}$ occurs at much higher temperatures (temperatures above $1300{ }^{\circ} \mathrm{C}$ ). Thus, decrease in the total nitrogen content in samples of liquid hydrocarbons obtained as a result of steam gasification (S1-S4) is the one of the main reasons for lower $\mathrm{NO}_{\mathrm{x}}$ concentration maximum compared to traditional fuel oil. It is also worth noting that the presence of water in S1-S4 samples contributed to the reduction in $\mathrm{NO}_{\mathrm{x}}$ emissions, due to the formation of additional $\mathrm{H}-$ and $\mathrm{OH}$ radicals, which can reduce $\mathrm{NO}$ and $\mathrm{SO}_{2}$ [46-47]. 
Formation of intensive microbursts during combustion of S1-S4 samples could also contribute to the reduction in the amount of $\mathrm{SO}_{2}$ and $\mathrm{NO}_{\mathrm{x}}$ released. This is due to the presence of water vapor formed during combustion of water-containing fuels (samples S1-S4), which affects the physical and chemical kinetics of combustion in the result of the decrease in the flame temperature assisted by water evaporation [48]. Thus, the lower temperature had an effect on reducing the rate of $\mathrm{NO}_{x}$ and $\mathrm{SO}_{2}$ release, since this process strongly depends on temperature [49].

Additionally, since the fuel was sprayed into smaller droplets (spark-like satellites) during microbursts, the reaction contact surface between the formed fuel droplets with $\mathrm{CO}$ and $\mathrm{H}_{2}$ increases, resulting in promotion of the reduction reaction of sulfur and nitrogen oxide:

$$
\begin{gathered}
\mathrm{SO}_{2}+3 \mathrm{CO} \rightarrow \mathrm{COS}+2 \mathrm{CO}_{2}[50], \\
\mathrm{NO}+\mathrm{CO} \rightarrow \mathrm{N}+\mathrm{CO}_{2}[51] .
\end{gathered}
$$

\section{The comparative analysis}

The differences between both physical and combustion characteristics of obtained liquid hydrocarbons and classical fuel oil were very significant. In order to consider the wide range of fuel characteristics, the simple comparison analysis methodic presented in $[45,52]$ was applied. It is based on the generalized indicator calculated according to following equation:

$$
A^{\text {relative }}=T_{g}^{\text {min_relative }}+Q^{\text {relative }}+\tau_{d 1}^{\text {relative }}+\tau_{d 1}^{\text {relative }}+\tau_{b}^{\text {relative }}+S O_{x}^{\text {relative }}+N O_{x}^{\text {relative }}+S^{\text {relative }}
$$

here $T_{g}^{\text {min_relative }}$ - relation between minimal ignition temperature of reference and studied samples, $Q^{\text {relative }}$ - relation between combustion heat of studied and reference samples, $\tau_{d 1}^{\text {relative }}$ - relation between homogeneous ignition delay times of reference and studied samples, $\tau_{d 2}^{\text {relative }}$ - relation between heterogeneous ignition delay times of reference and studied samples, $\tau_{b}^{\text {relative }}$ relation between combustion times of reference and studied samples, $S O_{x}^{\text {relative }}$ - relation between maximal concentration $\mathrm{SO}_{\mathrm{x}}$ during combustion of reference and studied samples, $N O_{x}^{\text {relative }}$ relation between maximal concentration $\mathrm{NO}_{\mathrm{x}}$ during combustion of reference and studied samples, $S^{\text {relative }}$ - relation between total costs of applying reference and studied samples. 
While the heterogeneous ignition delay times and cost of using corresponding fuel were not evaluated in current study the $\tau_{d 2}^{\text {relative }}$ and $S^{\text {relative }}$ were excluded from generalized indicator $A^{\text {relative }}$ calculation. However, some important for energy appliances properties of such fuels were not considered into $A^{\text {relative }}$, the fuel viscosity and pour point temperature, in particular. The lower viscosity allows decreasing heating of fuel before application while lower pour point simplifies conditions of its storage into cold regions. To take these factors into account the two additional terms were proposed:

$$
\begin{gathered}
T_{p p}^{\text {relative }}=\frac{T_{p p}^{\text {reference }}}{T_{p p}^{\text {studied }}} \\
v_{40}^{\text {relative }}=\frac{\ln v_{40}^{\text {reference }}}{\ln v_{40}^{\text {studied }} \mathrm{C}}
\end{gathered}
$$

here $T_{p p}^{\text {reference }}$ and $T_{p p}^{\text {studied }}$ - the pour point temperatures of reference and studied samples, $\mathrm{K}$; $v_{40}^{\text {reference }}$ and $v_{40}^{\text {studied }}$ C $\mathrm{C}$ - the dynamic viscosity of reference and studied samples at $40{ }^{\circ} \mathrm{C}, \mathrm{mPa} \cdot \mathrm{s}$. While the viscosity of samples changes with temperature following the exponential law, the viscosity factor was determined using natural logarithm of corresponding values. The modified complex indicator was calculated according to following formula:

$$
A_{\bmod }^{\text {relative }}=A^{\text {relative }}+T_{p p}^{\text {relative }}+v_{40}^{\text {relative }} \text {. }
$$

The S5 fuel oil sample was considered as the reference sample. Calculated using equations (1) and (4) the basic and modified complex indicator values are presented in Table 3.

Table 3 Basic and modified complex indicator values for obtained oil samples

\begin{tabular}{|c|c|c|c|c|c|c|}
\hline \multirow{2}{*}{ Sample } & \multicolumn{3}{|c|}{$A^{\text {relative }}$} & \multicolumn{3}{c|}{$A_{\text {mod }}^{\text {relative }}$} \\
\cline { 2 - 7 } & $500{ }^{\circ} \mathrm{C}$ & $600{ }^{\circ} \mathrm{C}$ & $700{ }^{\circ} \mathrm{C}$ & $500{ }^{\circ} \mathrm{C}$ & $600{ }^{\circ} \mathrm{C}$ & $700{ }^{\circ} \mathrm{C}$ \\
\hline S1 & 10.37 & 9.06 & 10.05 & 14.42 & 13.12 & 14.10 \\
\hline S2 & 11.28 & 9.56 & 8.46 & 15.34 & 13.62 & 12.51 \\
\hline S3 & 10.55 & 9.36 & 8.64 & 14.01 & 12.83 & 12.11 \\
\hline
\end{tabular}




\begin{tabular}{|l|l|l|l|l|l|l|}
\hline S4 & 9.42 & 9.17 & 8.63 & 13.15 & 12.90 & 12.36 \\
\hline
\end{tabular}

The basic and modified complex indicator values (8.46-15.34) revealed significant advantages of obtained samples in comparison with common fuel oil in studied temperature range. The $A^{\text {relative }}$ and $A_{\text {mod }}^{\text {relative }}$ values were decreasing with increasing in heating medium temperature. The modified complex criteria didn't reveal significant difference into samples evaluation compared to basic criteria but illustrated that application of S1-S4 oils will be even more advantageous due to lower viscosity and pour point temperature. The only exception was S1 sample: for it the highest values were observed at $500{ }^{\circ} \mathrm{C}$ while the lowest - at $600{ }^{\circ} \mathrm{C}$. The complex indicator values were varied in relatively narrow range for each sample and each temperature. According to both $A^{\text {relative }}$ and $A_{\bmod }^{\text {relative }}$ values at $500{ }^{\circ} \mathrm{C}$ and $600{ }^{\circ} \mathrm{C}$ the sample S2 was considered to be the most preferable, while at $700{ }^{\circ} \mathrm{C}$ it was sample $\mathrm{S} 1$. The least advantageous fuel at $500{ }^{\circ} \mathrm{C}$ was S4 sample. At 600 and $700{ }^{\circ} \mathrm{C}$ the performance of S2, S3 and S4 was nearly similar according to both $A^{\text {relative }}$ and $A_{\text {mod }}^{\text {relative }}$ criteria values.

\section{Conclusion}

A study on the physical-chemical characteristics and combustion parameters of the liquid hydrocarbons obtained by the method of steam gasification of used automobile tires had been carried out. The data obtained were compared with a sample of standard fuel oil, which is widespread in the energy industry.

1) Compared to standard fuel oil, the liquid hydrocarbons obtained by steam gasification of used tires were characterized by an almost similar calorific value (40.5-43.3 MJ/kg), lower viscosity $\left(10.6-18.8 \mathrm{~mm}^{2} / \mathrm{s}\right)$, sulfur content $(0.64-0.79 \mathrm{wt} \%)$, pour $\left(-43-(-52)^{\circ} \mathrm{C}\right)$ and flash $(73-$ $\left.85^{\circ} \mathrm{C}\right)$ points.

2) Unlike standard fuel oil, the ignition of liquid hydrocarbons was faster on average by $55.7 \%$ (in the temperature range $550-700{ }^{\circ} \mathrm{C}$ ), which was due to the lower viscosity and the presence of light hydrocarbons. 
3) Combustion of liquid hydrocarbons was accompanied by the formation of intense microexplosions, the epicenter of which was observed both on the surface and in the bulk of the sample. It was found that the duration of microexplosions and the area of propagation of the formed spark-like satellites significantly depended on the viscosity, as well as on the content of water and light hydrocarbons in the composition of the investigated fuel.

4) The total burning time for the fuel oil sample was higher by $30 \%$ on average. At the same time, with an increase in the temperature of the heating medium, for the samples of liquid hydrocarbons, the total combustion time was increased. This effect was associated with active coking of the sample surface in the result of a sharp increase in the heating medium temperature, which complicated the diffusional interaction between the oxidizer and the combustible components of liquid hydrocarbons.

5) In contrast to the standard fuel oil, for the samples of liquid hydrocarbons, lower values of the concentration maxima of the gas-phase products formed during combustion $\left(\mathrm{CO}, \mathrm{CO}_{2}, \mathrm{SO}_{2}\right.$, $\mathrm{NO}_{\mathrm{x}}$ ) were recorded. This was due to the difference in the elemental composition of the samples and their combustion patterns.

6) According to complex indicators calculated the combustion of obtained samples for energy production was much more advantageous compared to reference sample S5. The application of these fuels was found to be preferred at lower temperatures while the increasing temperature resulted into decline in complex indicator values by up to $25 \%$ and $19 \%$ for initial and modified complex criteria values, respectively.

Thus, steam gasification can be considered to be the effective method of recycling of used automobile tires to produce liquid hydrocarbon fuel, which, in turn, could be used as boiler fuel. The studied hydrocarbons have good practical prospects, since their combustion in the chambers of steam and water boilers will not require significant resources for their implementation at existing and projected heat power facilities. In addition, it is possible to obtain stable technical characteristics of liquid hydrocarbons when using a group of tires of the summer type, which are 
more widely used in the world, which is a very important technological factor for their application in the burners of power boilers.

\section{References:}

1. World passenger car production 2020. https://www.acea.be/statistics/article/world-passengercar-production, 2020 (accessed 27 December 2020).

2. Sienkiewicz, M., Janik, H., Borzędowska-Labuda, K., Kucińska-Lipka, J.: Environmentally friendly polymer-rubber composites obtained from waste tyres: A review. J. Clean. Prod. 147, 560-571 (2017). https://doi.org/10.1016/j.jclepro.2017.01.121.

3. Machin, E.B., Pedroso, D.T., de Carvalho, J.A.: Energetic valorization of waste tires. Renew. Sustain. Energy Rev. 68, 306-315 (2017). https://doi.org/10.1016/j.rser.2016.09.110.

4. Li, Q., Li, F., Meng, A., Tan, Z., Zhang, Y.: Thermolysis of scrap tire and rubber in sub/supercritical water. Waste Manag. 71, 311-319 (2018). nhttps://doi.org/10.1016/j.wasman.2017.10.017.

5. Funazukuri, T., Takanashi, T., Wakao, N.: Supercritical extraction of used automotive tire with water. J. Chem. Eng. Japan. 20, 23-27 (1987). https://doi.org/10.1252/jcej.20.23.

6. Moulin, L., Da Silva, S., Bounaceur, A., Herblot, M., Soudais, L.: Assessment of recovered carbon black obtained by waste tires steam water thermolysis: an industrial application. Waste Biomass. Valori. 8, 2757-2770 (2017). https://doi.org/10.1007/s12649-016-9822-8.

7. Jonusas, A., Miknius, L.: Effect of the pressure and feedstock state on the yield and properties of waste tire thermolysis products. Energy Fuels 28, 2465-2471 (2014). https://doi.org/10.1021/ef500289a.

8. Martínez, J.D., Cardona-Uribe, N., Murillo, R., García, T., López, J.M.: Carbon black recovery from waste tire pyrolysis by demineralization: Production and application in rubber compounding. Waste Manag. 85, 574-584 (2019). https://doi.org/10.1016/j.wasman.2019.01.016.

9. Jeyakumar, N., Narayanasamy, B., John, K., Kathiresh, Markus Solomon, J.: Preparation, characterization and effect of calcium carbonate and titanium dioxide nano additives on fuel properties of tire oil diesel blend. Energy Sources, Part A Recover. Util. Environ. Eff. 40, 1798- 
1806 (2018). https://doi.org/10.1080/15567036.2018.1486919.

10. Williams, P.T.: Pyrolysis of waste tyres: A review. Waste Manag. 33, 1714-1728 (2013). https://doi.org/10.1016/j.wasman.2013.05.003.

11. Frigo, S., Seggiani, M., Puccini, M., Vitolo, S.: Liquid fuel production from waste tyre pyrolysis and its utilisation in a diesel engine. Fuel 116, 399-408 (2014). https://doi.org/10.1016/j.fuel.2013.08.044.

12. Rutkowski, P., Kubacki, A.: Influence of polystyrene addition to cellulose on chemical structure and properties of bio-oil obtained during pyrolysis. Energy Convers. Manag. 47, 716731 (2006). https://doi.org/10.1016/j.enconman.2005.05.017.

13. Pradhan, D., Singh, R.K.: Thermal pyrolysis of bicycle waste tyre using batch reactor. Int. J. Chem. Eng. Appl. 2, 332-336 (2011). https://doi.org/10.7763/IJCEA.2011.V2.129.

14. Martínez, J.D., Puy, N., Murillo, T. García, R., Navarro, M.V., Mastral, A.M.: Waste tyre pyrolysis - A review. Renew. Sustain. Energy Rev. 23, 179-213 (2013). https://doi.org/10.1016/j.rser.2013.02.038.

15. Zahir Hussain, A., Santhoshkumar, A., Ramanathan, A., Assessment of pyrolysis waste engine oil as an alternative fuel source for diesel engine. J. Therm. Anal. Calorim. 141, 2277-2293 (2020). https://doi.org/10.1007/s10973-020-09516-y.

16. Ikegami, M., Xu, G., Ikeda, K., Honma, S., Nagaishi, H., Dietrich, D. L., Takeshita, Y.: Distinctive combustion stages of single heavy oil droplet under microgravity. Fuel 82, 293-304 (2003) https://doi.org/10.1016/S0016-2361(02)00257-0.

17. Osayi, J.I., Iyuke, S., Daramola, M.O., Osifo, P., Van Der Walt, I.J., Ogbeide, S.E.: Evaluation of pyrolytic oil from used tires and natural rubber (Hevea brasiliensis). Chem. Eng. Commun. 205, 805-821 (2018). https://doi.org/10.1080/00986445.2017.1422493.

18. Karagöz, M., Ağbulut, Ü., Sarıdemir, S.: Waste to energy: Production of waste tire pyrolysis oil and comprehensive analysis of its usability in diesel engines. Fuel 275, 117844 (2020). https://doi.org/10.1016/j.fuel.2020.117844. 
19. Miandad, R., Barakat, M.A., Aburiazaiza, A.S., Rehan, M., Ismail, I.M.I., Nizami, A.S.: Effect of plastic waste types on pyrolysis liquid oil. Int. Biodeterior. Biodegradation. 119, 239-252 (2017). https://doi.org/10.1016/j.ibiod.2016.09.017.

20. Broumand, M., Shahzeb Khan, M., Yun, S., Hong, Z., Thomson, M.J.: The role of atomization in the spray combustion of a fast pyrolysis bio-oil. Fuel 276, 118035 (2020). https://doi.org/10.1016/j.fuel.2020.118035.

21. Muelas, Á., Callén, M.S., Murillo, R., Ballester, J.: Production and droplet combustion characteristics of waste tire pyrolysis oil. Fuel Process. Technol. 196, 106149 (2019). https://doi.org/10.1016/j.fuproc.2019.106149.

22. Wornat, M.J., Porter, B.G., Yang, N.Y.C.: Single droplet combustion of biomass pyrolysis oils. Energy Fuels 8, 1131-1142 (1994). https://doi.org/10.1021/ef00047a018.

23. Calabria, R., Chiariello, F., Massoli, P.: Combustion fundamentals of pyrolysis oil based fuels. Exp. Therm. Fluid Sci. 31, 413-420 (2007). https://doi.org/10.1016/j.expthermflusci.2006.04.010. 24. Hou, S.S., Rizal, F.M., Lin, T.H., Yang, T.Y., Wan, H.P.: Microexplosion and ignition of droplets of fuel oil/bio-oil (derived from lauan wood) blends. Fuel 113, 31-42 (2013). https://doi.org/10.1016/j.fuel.2013.05.066.

25. Kuan, Y.H., Wu, F.H., Chen, G.B., Lin, H.T., Lin, T.H.: Study of the combustion characteristics of sewage sludge pyrolysis oil, heavy fuel oil, and their blends. Energy 201, 117559 (2020). https://doi.org/10.1016/j.energy.2020.117559.

26. Chen, G.B., Li, Y.H., Lan, C.H., Lin, H.T., Chao, Y.C.: Micro-explosion and burning characteristics of a single droplet of pyrolytic oil from castor seeds. Appl. Therm. Eng. 114, 10531063 (2017). https://doi.org/10.1016/j.applthermaleng.2016.12.052.

27. Wang, J., Qiao, X., Ju, D., Sun, C., Wang, T.: Bubble nucleation, micro-explosion and residue formation in superheated jatropha oil droplet: the phenomena of vapor plume and vapor cloud. Fuel 261, 116431 (2020). https://doi.org/10.1016/j.fuel.2019.116431.

28. Yang, S.I., Wu, M.S.: The droplet combustion and thermal characteristics of pinewood bio- 
oil from slow

pyrolysis.

Energy

141 ,

$2377-2386$

(2017).

https://doi.org/10.1016/j.energy.2017.11.119.

29. Glushkov, D.O., Feoktistov, D.V., Kuznetsov, G.V., Batishcheva, K.A., Kudelova, T., Paushkina, K.K.: Conditions and characteristics of droplets breakup for industrial waste-derived fuel suspensions ignited in high-temperature air. Fuel 265, 116915 (2020). https://doi.org/10.1016/j.fuel.2019.116915.

30. Valiullin, T.R., Vershinina, K.Y., Kuznetsov, G.V., Strizhak, P.A.: An experimental investigation into ignition and combustion of groups of slurry fuel droplets containing high concentrations of water. Fuel Process. Technol. 210, $106553 \quad$ (2020). https://doi.org/10.1016/j.fuproc.2020.106553.

31. Glushkov, D.O., Kuznetsov, G.V., Nigay, A.G., Yanovsky, V.A.: Influence of gellant and drag-reducing agent on the ignition characteristics of typical liquid hydrocarbon fuels. Acta Astronaut. 177, 66-79 (2020). https://doi.org/10.1016/j.actaastro.2020.07.018.

32. Solé, J., García-Olivares, A., Turiel, A., Ballabrera-Poy, J.: Renewable transitions and the net energy from oil liquids: A scenarios study. Renew. Energy 116, 258-271 (2018). https://doi.org/10.1016/j.renene.2017.09.035.

33. Liu, D., Tang, J., Zheng, R., Song, Q.: Song, Influence of steam on the coking characteristics of heavy oil during in situ combustion. Fuel 264, 116904 (2020). https://doi.org/10.1016/j.fuel.2019.116904.

34. Shyu, R.R., Chen,C.S., Goudie, G.O., El-Wakil, M.M.: Multi-component heavy fuel drop histories in a high-temperature flow field. Fuel 51, 135-145 (1974). https://doi.org/10.1016/00162361(72)90064-6.

35. Mahmoudi, A.H., Pozarlik, A.K., van der Weide, E., Kersten, S.R.A., Luding, S., Brem, G.: Effect of char on the combustion process of multicomponent bio-fuel. Chem. Eng. Sci. 175, 286295 (2018). https://doi.org/10.1016/j.ces.2017.09.053.

36. Porfiryev, Y., Shuvalov, S., Popov, P., Kolybelsky, D., Petrova, D., Ivanov, E., Tonkonogov, 
B., Vinokurov, V.: Effect of base oil nature on the operational properties of low-temperature greases. ACS Omega 5, 11946-11954 (2020). https://doi.org/10.1021/acsomega.9b04087.

37. Labaki, M., Jeguirim, M.: Thermochemical conversion of waste tyres - a review. Environ. Sci. Pollut. Res. 24, 9962-9992 (2017). https://doi.org/10.1007/s11356-016-7780-0.

38. Tipler, S., Mergulhão, C.S., Vanhove, G., Van Haute, Q., Contino, F., Coussement, A.: Ignition study of an oxygenated and high-alkene light petroleum fraction produced from automotive $\begin{array}{llllll}\text { shredder } & \text { residues. } & \text { Energy } & \text { Fuels } & 33, & 5664-5672\end{array}$ https://doi.org/10.1021/acs.energyfuels.9b00649.

39. Viswanathan, B.: Petroleum. In: Viswanathan, B. Energy Sources, pp. 29-57. Elsevier, Amsterdam (2017). https://doi.org/10.1016/B978-0-444-56353-8.00002-2.

40. Glushkov, D.O., Kuznetsov, G.V., Nigay, A.G., Yanovsky, V.A., Yashutina, O.S.: Ignition mechanism and characteristics of gel fuels based on oil-free and oil-filled cryogels with fine coal particles. Powder Technol. 360, 65-79 (2020). https://doi.org/10.1016/j.powtec.2019.09.081.

41. Alvarez, J., Lopez, G., Amutio, M., Mkhize, N.M., Danon, B., van der Gryp, P., Görgens, J.F., Bilbao, J., Olazar, M.: Evaluation of the properties of tyre pyrolysis oils obtained in a conical spouted bed reactor. Energy 128, 463-474 (2017). https://doi.org/10.1016/j.energy.2017.03.163.

42. Wang, C.H., Liu, X.Q., Law, C.K.: Combustion and microexplosion of freely falling multicomponent droplets. Combust. Flame. 56, 175-197 (1984). https://doi.org/10.1016/00102180(84)90036-1.

43. Baert, R.S.G.: A mathematical model for heavy fuel droplet vaporization and pyrolysis in a high temperature inert gas. Combust. Sci. Technol. 90, 125-147 (1993). https://doi.org/10.1080/00102209308907607.

44. Vershinina, K.Y., Dorokhov, V.V., Romanov, D.S., Strizhak, P.A.: Comparing the ignition parameters of promising coal fuels. Process. Saf. Environ. Prot. 139, 273-282 (2020). https://doi.org/10.1016/j.psep.2020.04.027.

45. Nyashina, G.S., Vershinina, K.Y., Strizhak, P.A.: Impact of micro-explosive atomization of 
fuel droplets on relative performance indicators of their combustion. Fuel Process. Technol. 201, 106334 (2020). https://doi.org/10.1016/j.fuproc.2019.106334.

46. Daood, S.S., Ord, G., Wilkinson, T., Nimmo, W.: Fuel additive technology - $\mathrm{NO}_{\mathrm{x}}$ reduction, combustion efficiency and fly ash improvement for coal fired power stations. Fuel 134, 293-306 (2014). https://doi.org/10.1016/j.fuel.2014.04.032.

47. Feng, T., Huo, M., Zhao, X., Wan, T., Xia, X., Ma, C.: Reduction of $\mathrm{SO}_{2}$ to elemental sulfur with $\mathrm{H}_{2}$ and mixed $\mathrm{H}_{2} / \mathrm{CO}$ gas in an activated carbon bed. Chem. Eng. Res. Des. 121, 191-199 (2017). https://doi.org/10.1016/j.cherd.2017.03.014.

48. Mwangi, J.K., Lee, W.J., Chang, Y.C., Chen, C.Y., Wang, L.C.: An overview: Energy saving and pollution reduction by using green fuel blends in diesel engines. Appl. Energy. 159, 214-236 (2015). https://doi.org/10.1016/j.apenergy.2015.08.084.

49. Zhao, B., Su, Y., Liu, D., Zhang, H., Liu, W., Cui, G.: $\mathrm{SO}_{2} / \mathrm{NO}_{\mathrm{x}}$ emissions and ash formation from algae biomass combustion: Process characteristics and mechanisms. Energy 113, 821-830 (2016). https://doi.org/10.1016/j.energy.2016.07.107.

50. Zhang, Z., Chen, D., Li, Z., Cai, N., Imada, J.: Development of sulfur release and reaction model for computational fluid dynamics modeling in sub-bituminous coal combustion. Energy Fuels. 31, 1383-1398 (2017). https://doi.org/10.1021/acs.energyfuels.6b02867.

51. H Zhou, H., Li, Y., Li, N., Qiu, R., Cen, K.: Conversions of fuel-N to NO and $\mathrm{N}_{2} \mathrm{O}$ during devolatilization and char combustion stages of a single coal particle under oxy-fuel fluidized bed conditions. J. Energy Inst. 92, 351-363 (2019). https://doi.org/10.1016/j.joei.2018.01.001.

52. Nyashina, G.S., Kurgankina, M.A., Strizhak, P.A.: Environmental, economic and energetic benefits of using coal and oil processing waste instead of coal to produce the same amount of energy. Energy Convers. Manag., 174, $\quad$ 175-187

(2018). https://doi.org/10.1016/j.enconman.2018.08.048. 


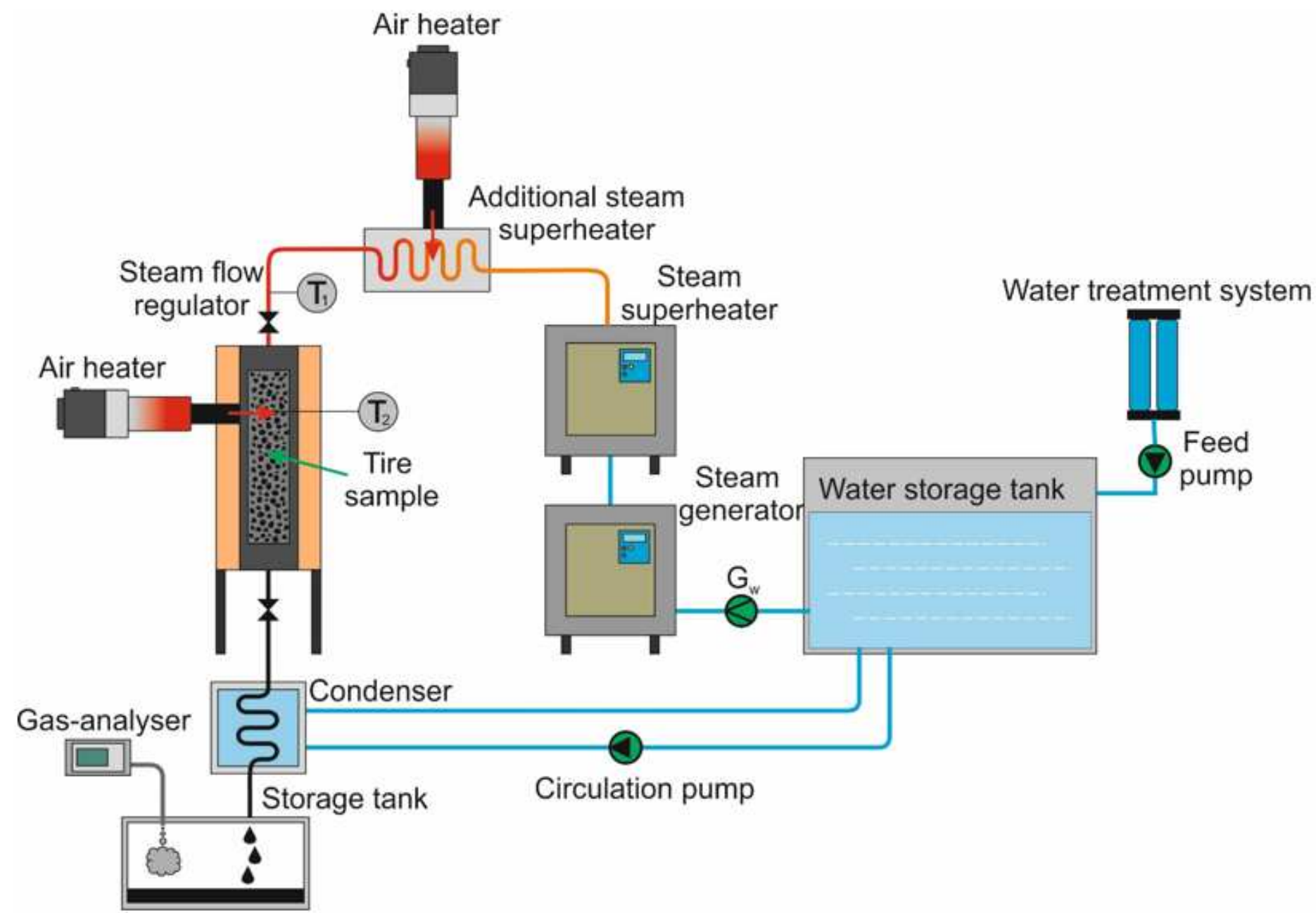

Figure 1

Schematic diagram of the experimental setup used for steam gasification of used automobile tires. 


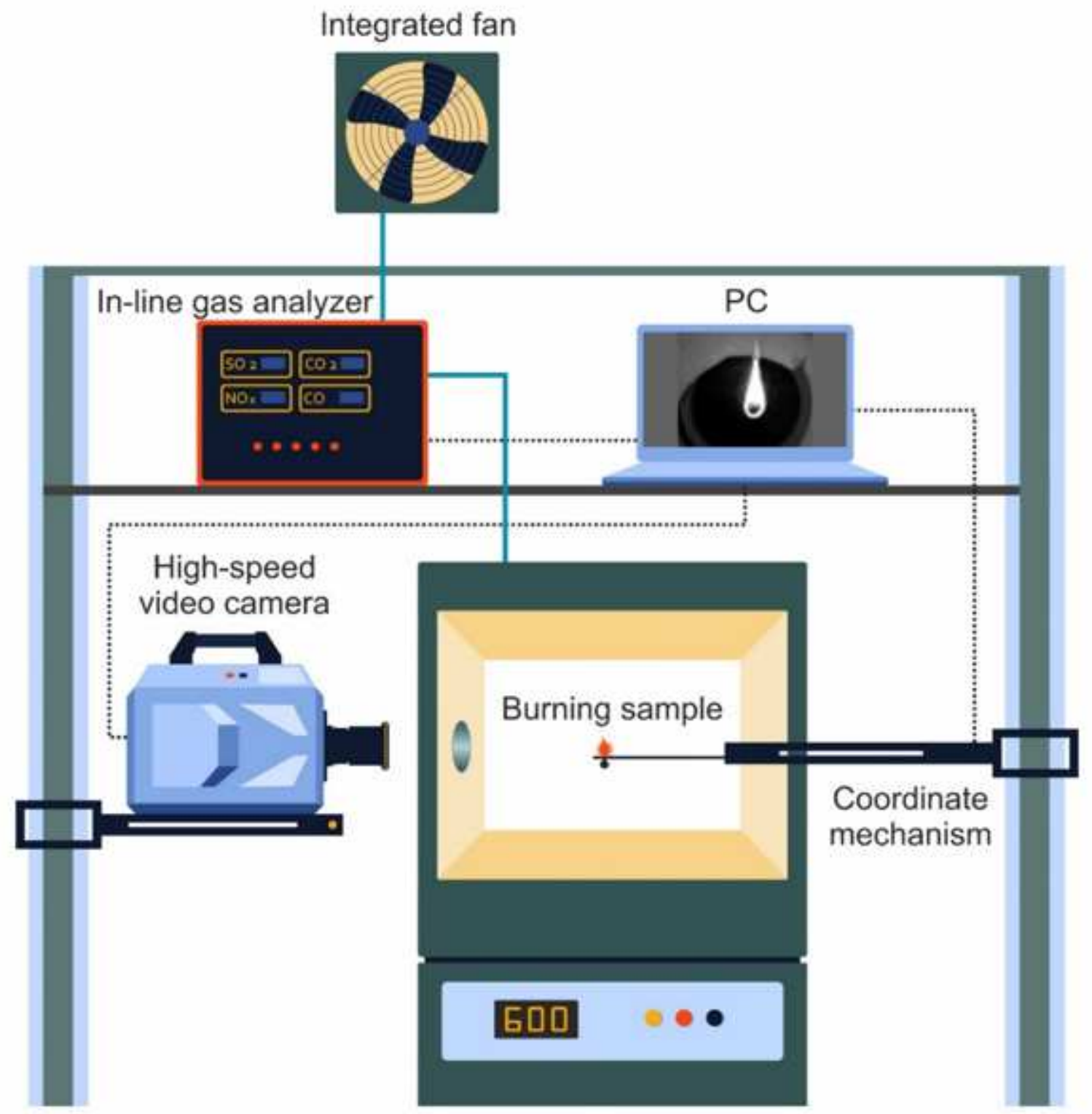

Figure 2

Experimental setup for studying the combustion of liquid fuel droplets. 


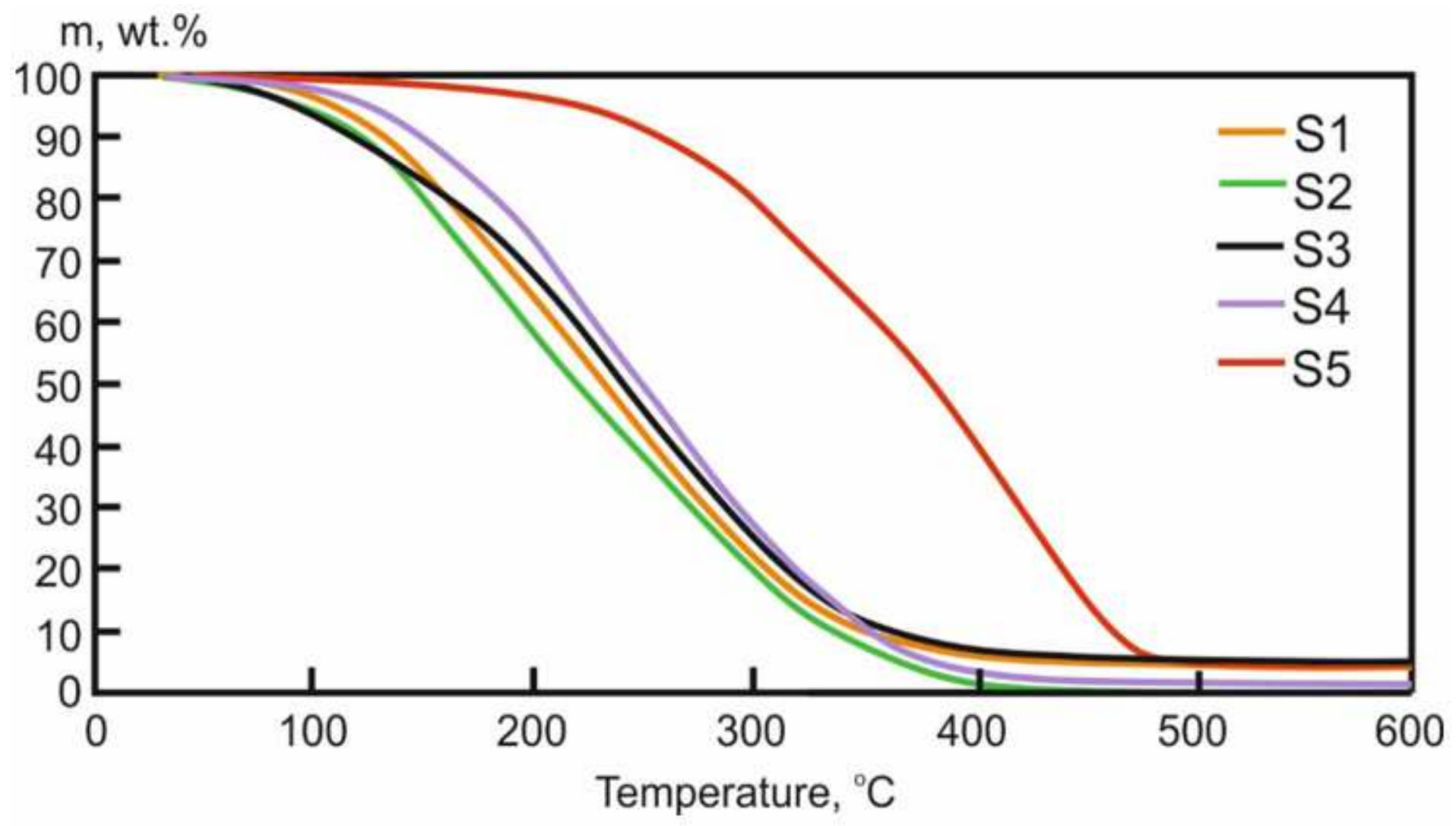

Figure 3

TG curves for thermal decomposition of liquid hydrocarbon samples. Medium - argon $150 \mathrm{ml} / \mathrm{min}$, heating rate $-10^{\circ} \mathrm{C} / \mathrm{min}$, sample weight $\approx 20 \mathrm{mg}$.

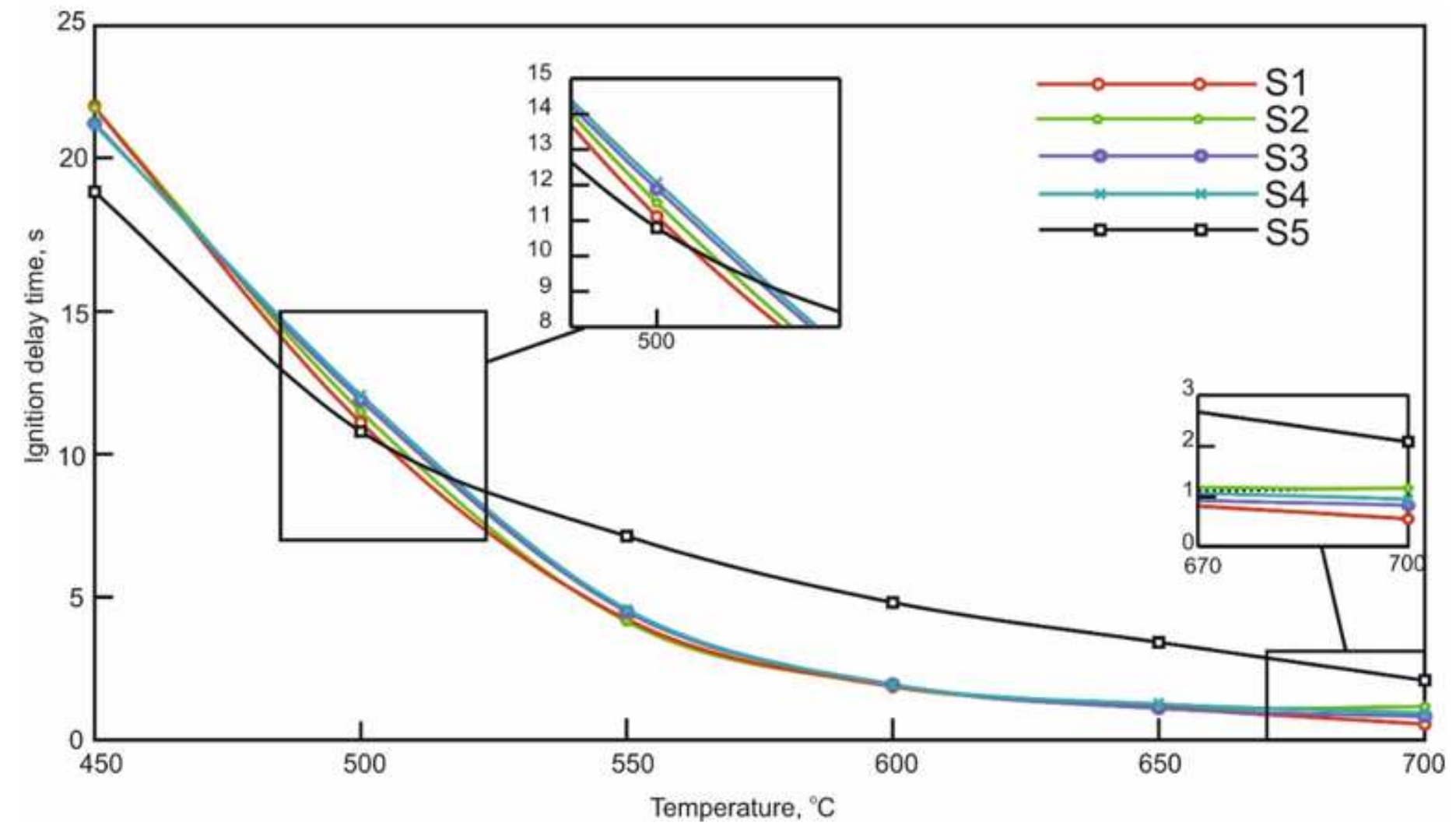




\section{Figure 4}

Dependences of the ignition delay time of the studied hydrocarbon droplets on the heating medium temperature in range from 450 to $700{ }^{\circ} \mathrm{C}$.
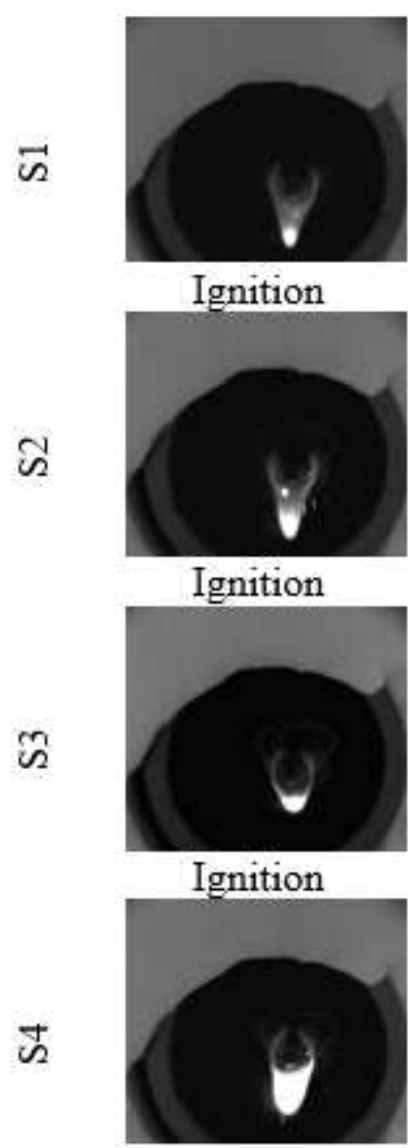

Ignition

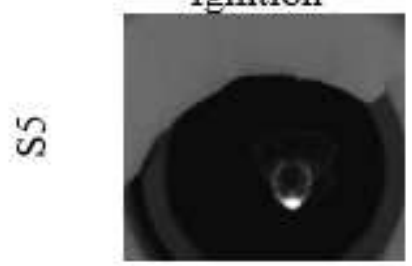

Ignition

a

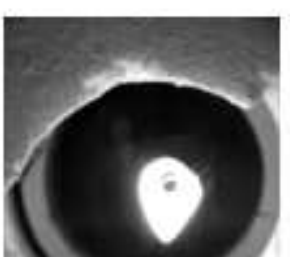

$\tau \approx 0.01 \mathrm{~s}$

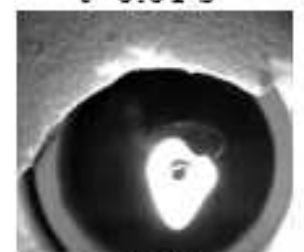

$\tau \approx 0.02 \mathrm{~s}$

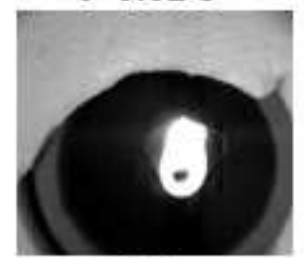

$\tau \approx 0.03 \mathrm{~s}$

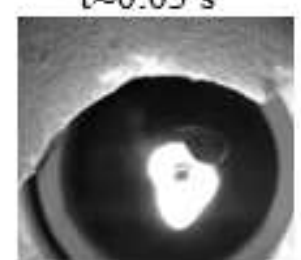

$\tau \approx 0.01 \mathrm{~s}$

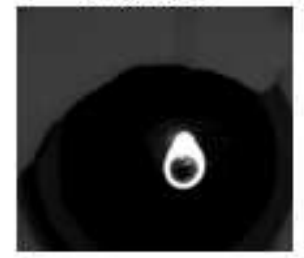

$\tau \approx 0.19 \mathrm{~s}$

b

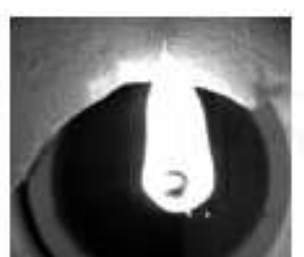

$\tau \approx 0.14 \mathrm{~s}$

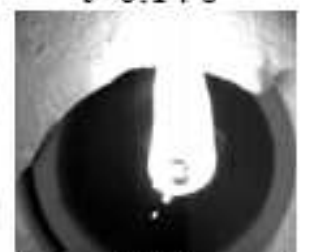

$\tau \approx 0.25 \mathrm{~s}$

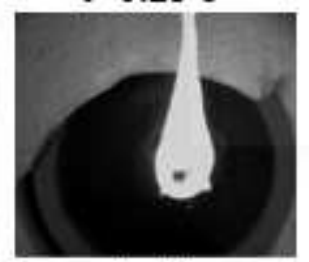

$\tau \approx 0.25 \mathrm{~s}$

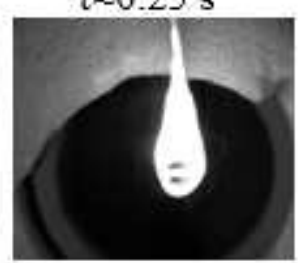

$\tau \approx 0.21 \mathrm{~s}$

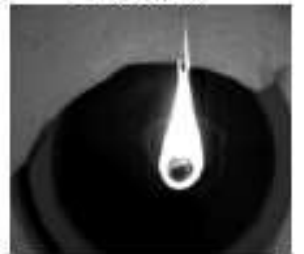

$\tau \approx 1.90 \mathrm{~s}$

c

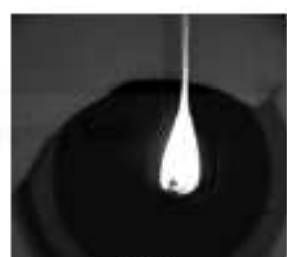

$\tau \approx 3.48 \mathrm{~s}$

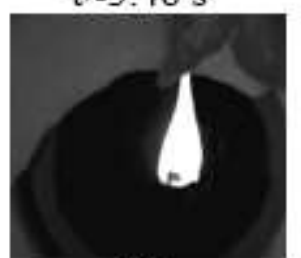

$\tau \approx 3.74 \mathrm{~s}$

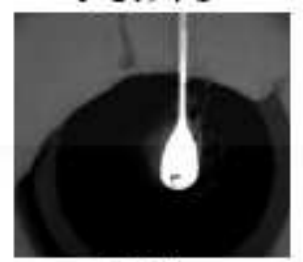

$\tau \approx 3.74 \mathrm{~s}$

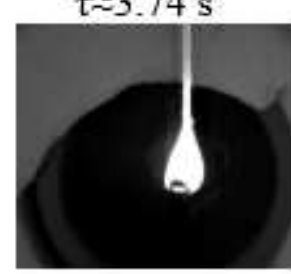

$\tau \approx 3.65 \mathrm{~s}$

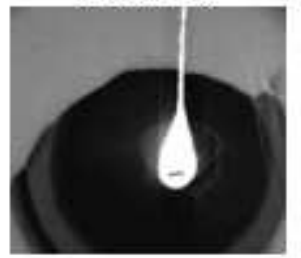

$\tau \approx 4.45 \mathrm{~s}$

d

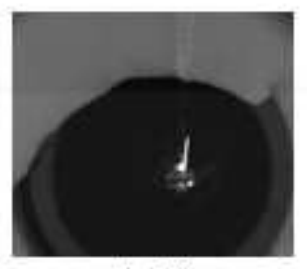

$\tau \approx 4.28 \mathrm{~s}$

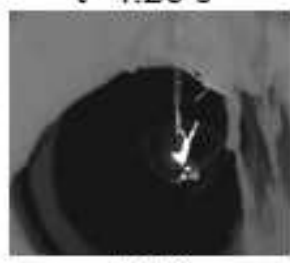

$\tau \approx 4.36 \mathrm{~s}$

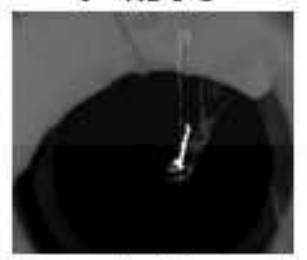

$\tau \approx 4.16 \mathrm{~s}$

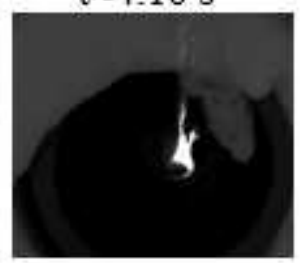

$\tau \approx 4.23 \mathrm{~s}$

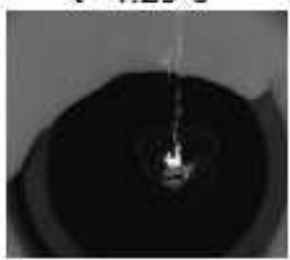

$\tau \approx 4.85 \mathrm{~s}$

e

\section{Figure 5}

Typical video frames of ignition and subsequent combustion of hydrocarbon droplets at $700{ }^{\circ} \mathrm{C}$ temperature of the heating medium ( $a$ - ignition, $b$ - flame formation, followed by expansion of the combustion front, $\mathrm{c}$ - increase in the intensity of flaming combustion, $\mathrm{d}$ - constriction of the combustion front, e - formation of the coke residue). 


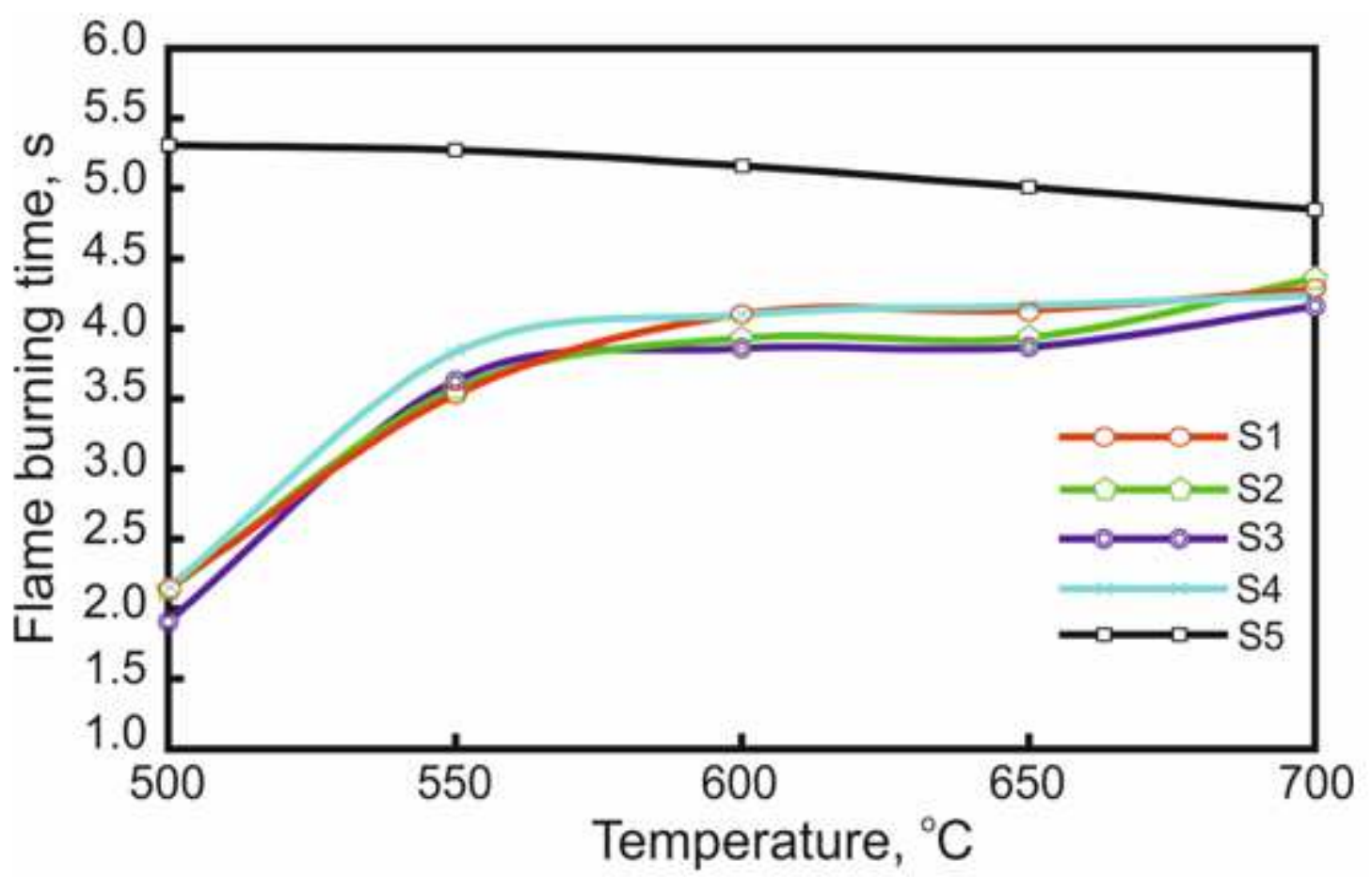

Figure 6

Dependences of the flame burning time of the liquid hydrocarbon droplets on the heating medium temperature in range from 500 to $700{ }^{\circ} \mathrm{C}$.
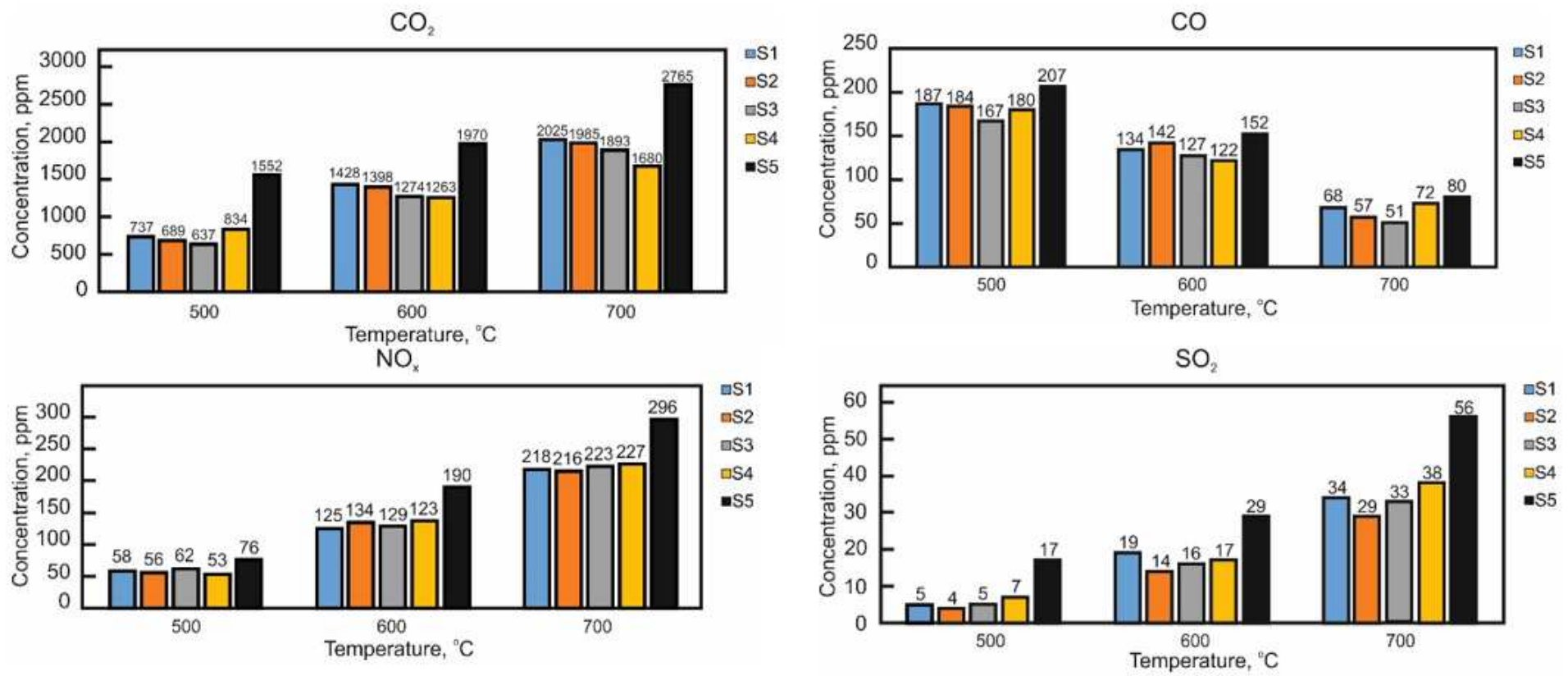

Figure 7

Concentration maxima of gas-phase compounds ( $\mathrm{CO}, \mathrm{CO} 2, \mathrm{SO} 2$ and $\mathrm{NOx}$ ) in the released combustion products of liquid hydrocarbons at different temperatures of the heating medium. 
This is a list of supplementary files associated with this preprint. Click to download.

- Graphicalabstract.docx 